\title{
Catalytic Synthesis of Oligosiloxanes Mediated by an Air Stable Catalyst, $\left(\mathrm{C}_{6} \mathrm{~F}_{5}\right)_{3} \mathrm{~B}\left(\mathrm{OH}_{2}\right)$
}

\author{
Kristel M. Rabanzo-Castillo ${ }^{1,2}$, Vipin B. Kumar ${ }^{1,2}$, Tilo Söhnel ${ }^{1,2}$ and Erin M. Leitao ${ }^{1,2 *}$ \\ ${ }^{1}$ School of Chemical Sciences, University of Auckland, Auckland, New Zealand, ${ }^{2}$ The MacDiarmid Institute for Advanced \\ Materials and Nanotechnology, Auckland, New Zealand
}

\section{OPEN ACCESS}

Edited by:

Eugene A. Goodilin,

Lomonosov Moscow State

University, Russia

Reviewed by:

Grzegorz Hreczycho, Adam Mickiewicz University, Poland

Aziz M. Muzafarov,

A. N. Nesmeyanov Institute of Organoelement Compounds

(RAS), Russia

*Correspondence: Erin M. Leitao

erin.leitao@auckland.ac.nz

Specialty section:

This article was submitted to Green and Sustainable Chemistry,

a section of the journal

Frontiers in Chemistry

Received: 14 March 2020 Accepted: 08 May 2020

Published: 23 June 2020

Citation:

Rabanzo-Castillo KM, Kumar VB,

Söhnel T and Leitao EM (2020) Catalytic Synthesis of Oligosiloxanes Mediated by an Air Stable Catalyst, $\left(\mathrm{C}_{6} F_{5}\right)_{3} \mathrm{~B}\left(\mathrm{OH}_{2}\right)$. Front. Chem. 8:477. doi: 10.3389/fchem.2020.00477
The utility of $\left(\mathrm{C}_{6} \mathrm{~F}_{5}\right)_{3} \mathrm{~B}\left(\mathrm{OH}_{2}\right)$ as catalyst for the simple and environmentally benign synthesis of oligosiloxanes directly from hydrosilanes, is reported. This protocol offers several advantages compared to other methods of synthesizing siloxanes, such as mild reaction conditions, low catalyst loading, and a short reaction time with high yields and purity. The considerable $\mathrm{H}_{2} \mathrm{O}$-tolerance of $\left(\mathrm{C}_{6} \mathrm{~F}_{5}\right)_{3} \mathrm{~B}\left(\mathrm{OH}_{2}\right)$ promoted a catalytic route to disiloxanes which showed $>99 \%$ conversion of three tertiary silanes, $\mathrm{Et}_{3} \mathrm{SiH}, \mathrm{PhMe}_{2} \mathrm{SiH}$, and $\mathrm{Ph}_{3} \mathrm{SiH}$. Preliminary data on the synthesis of unsymmetrical disiloxanes (Si-O-Si') suggests that by modifying the reaction conditions and/or using a 1:1 combination of silane to silanol the cross-product can be favored. Intramolecular reactions of disilyl compounds with catalytic $\left(\mathrm{C}_{6} \mathrm{~F}_{5}\right)_{3} \mathrm{~B}\left(\mathrm{OH}_{2}\right)$ led to the formation of novel bridged siloxanes, containing a Si-O-Si linkage within a cyclic structure, as the major product. Moreover, the reaction conditions enabled recovery and recycling of the catalyst. The catalyst was re-used 5 times and demonstrated excellent conversion for each substrate at $1.0 \mathrm{~mol} \%$ catalyst loading. This seemingly simple reaction has a rather complicated mechanism. With the hydrosilane $\left(\mathrm{R}_{3} \mathrm{SiH}\right)$ as the sole starting material, the fate of the reaction largely depends on the creation of silanol $\left(\mathrm{R}_{3} \mathrm{SiOH}\right)$ from $\mathrm{R}_{3} \mathrm{SiH}$ as these two undergo dehydrocoupling to yield a disiloxane product. Generation of the silanol is based on a modified Piers-Rubinsztajn reaction. Once the silanol has been produced, the mechanism involves a series of competitive reactions with multiple catalytically relevant species involving water, silane, and silanol interacting with the Lewis acid and the favored reaction cycle depends on the concentration of various species in solution.

Keywords: siloxane, lewis acid catalysis, dehydrocoupling, catalyst recycling, silane, competing mechanisms

\section{INTRODUCTION}

Organo(poly)siloxanes (silicones), bearing the repeating Si-O bond motif, are considered one of the most important classes of functional materials that have influenced many technological industries (Sawama et al., 2016; Wang et al., 2017). Industrially, polysiloxanes are generated by acid- or base-catalyzed ring opening polymerization of cyclic siloxanes, or by hydrolysis of chlorosilanes (Grubb, 1954; Brinker and Scherer, 1990). However, these methods have limited control over the oligomeric or polymeric siloxane sequence being formed. The substitution process is catalyzed either by an acid or a base under equilibrium in which the polysiloxanes can also be degraded (Brinker and Scherer, 1990). Although a step-wise synthesis of oligosiloxane has been reported, it is still based on conventional 
condensation of silanols with chlorosilanes (Uchida et al., 1990; Matsumoto et al., 2018, 2019). Other methods available in literature for the preparation of oligosiloxanes involve catalytic cross-coupling reactions of oxygen nucleophiles (e.g., alkoxysilanes, silanols, phenols, and ethers) with hydrosilanes (Brook, 2018; Zhang et al., 2020). The synthesis of symmetrical disiloxanes directly from hydrosilanes have been reported using $\mathrm{InBr}_{3}$, a reaction which involves Lewis acid-catalyzed air oxidation of hydrosilanes (Scheme 1, A, conditions I) (Sridhar et al., 2009). Reduction of $\mathrm{CO}_{2}$ with hydrosilanes and a zirconium complex $/ \mathrm{B}\left(\mathrm{C}_{6} \mathrm{~F}_{5}\right)_{3}$ as the catalyst have also been reported to produce methane and oligosiloxanes as products (Matsuo and Kawaguchi, 2006). Other direct syntheses reported the use of $\mathrm{H}_{2} \mathrm{O}$ as the solvent and oxidant, however, generally these involved expensive transition metal catalysts and are conducted at elevated temperature (Scheme 1, A, conditions II-IV) (Lee et al., 2000, 2004; Ison et al., 2005; Mitsudome et al., 2008, 2009; Chauhan et al., 2009; Asao et al., 2010; John et al., 2011; Tan et al., 2011; Jeon et al., 2012; Shimizu et al., 2012a,b; Liu et al., 2014; Sawama et al., 2016; Tsuchido et al., 2020). The development of synthetic methods catalyzed by abundant and cheap basemetal complexes then emerged to form symmetrical and unsymmetrical disiloxanes and other oligosiloxanes (Pattanaik and Gunanathan, 2019) (Scheme 1, B, conditions V). Catalytic routes toward unsymmetrical siloxanes ( $\mathrm{Si}-\mathrm{O}-\mathrm{Si}^{\prime}$ ) have also been demonstrated (Scheme 1, B, conditions VI-VIII) using Sc(OTf) 3 (Hreczycho et al., 2013; Hreczycho, 2015), Nafion (Kaźmierczak and Hreczycho, 2018), or Amberlyst-15 (Kuciński and Hreczycho, 2019a) with silanols and alkylsilanes at room temperature. Transition metal catalyzed routes to unsymmetrical disiloxanes have been achieved through Pd-catalyzed arylation of hydroxysiloxanes (Kurihara et al., 2013), nonhydrolytic Pd/Ccatalyzed cross-coupling reactions (Igarashi et al., 2014), Bamediated dehydrocoupling of hydrosilanes and silanols (Le Coz et al., 2019) and silylation of silanols catalyzed by a ruthenium complex (Marciniec et al., 2008). Other routes to form Si-O-Si' bonds include the use of fluoride and azidosilanes (Abele et al., 2003) as well as a catalyst-free, chlorine-free option using disilazanes (Kuciński and Hreczycho, 2019b) (Scheme 1, B, conditions IX-X).

Main group (and metal-free) catalysts such as $\mathrm{B}\left(\mathrm{C}_{6} \mathrm{~F}_{5}\right)_{3}$ have gained great interest as a catalyst activator and as strong Lewis acid for many purposes (Piers, 2004; Lawson and Melen, 2017; Brook, 2018). Several studies have been published for the

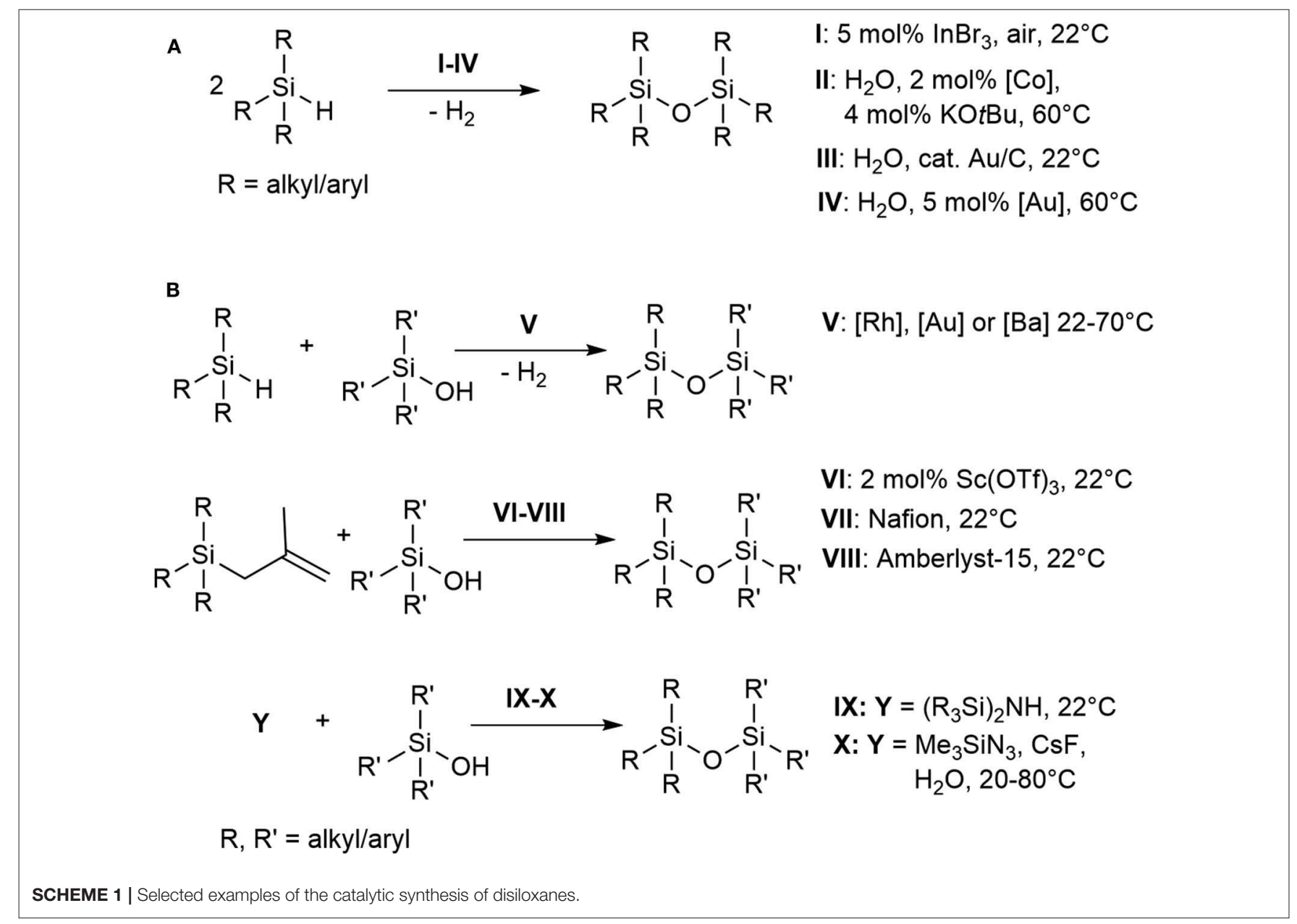


preparation of siloxanes and hyperbranched siloxanes involving catalytic cross-coupling reactions of oxygen nucleophiles (e.g., alkoxysilanes, silanols, phenols, and ethers) with hydrosilanes (Kawakami et al., 2004; Chojnowski et al., 2005, 2006, 2008; Zhou and Kawakami, 2005; Shinke et al., 2007; Thompson and Davies, 2007; Cella and Rubinsztajn, 2008; Kurjata et al., 2009; Feghali and Cantat, 2014; Madsen et al., 2014; Zhang et al., 2014, 2020; Feghali et al., 2015; Laengert et al., 2017; Szawiola et al., 2017; Wu et al., 2017; Brook, 2018; Ai et al., 2019). Recently, Matsumoto and co-workers reported a sequencecontrolled synthesis of oligosiloxanes via dehydrocarbonative coupling of alkoxysilanes and hydrosilanes, named the PiersRubinsztajn reaction, and also via hydrosilylation of carbonyl compounds using $\mathrm{B}\left(\mathrm{C}_{6} \mathrm{~F}_{5}\right)_{3}$ (Matsumoto et al., 2018). Several mechanistic studies have been demonstrated for the formation of siloxanes depending on the type of substrates and catalysts used (Brook, 2018; Pattanaik and Gunanathan, 2019). The standard Piers-Rubinsztajn reaction involves the condensation of a hydrosilane $\left(\mathrm{R}_{3} \mathrm{SiH}\right)$ and alkoxysilane $\left(\mathrm{R}_{3} \mathrm{SiOR}\right)$ to form a siloxane, with subsequent removal of an alkane, $\mathrm{RH}(\mathrm{R}=$ alkyl/aryl). Knowledge of this mechanism has allowed for the design of controlled synthetic routes to polysiloxanes using $\mathrm{B}\left(\mathrm{C}_{6} \mathrm{~F}_{5}\right)_{3}$ as the catalyst (Chojnowski et al., 2005; Rubinsztajn and Cella, 2005; Cella and Rubinsztajn, 2008; Yi et al., 2018; Schneider et al., 2019). The strong affinity of $\mathrm{B}\left(\mathrm{C}_{6} \mathrm{~F}_{5}\right)_{3}$ with $\mathrm{H}_{2} \mathrm{O}$ can lead to the formation of Brønsted acids which seems to not be a problem in terms of siloxane or polymer synthesis (Neumann et al., 2004; Chojnowski et al., 2005; Longuet et al., 2007). However, $\mathrm{B}\left(\mathrm{C}_{6} \mathrm{~F}_{5}\right)_{3}$ can form several complexes with $\mathrm{H}_{2} \mathrm{O}$ which serve to remove the active catalyst from the reaction (Brook, 2018). In the presence of excess $\mathrm{H}_{2} \mathrm{O}$ therefore, the Piers-Rubinsztajn reaction is not observed or leads to lower rate of reaction.

In this article, we report the synthesis of oligomeric siloxanes starting from hydrosilanes and tethered hydrosilanes using controlled amounts of $\mathrm{H}_{2} \mathrm{O}$. Specifically, we explored the possibility of replacing the $\mathrm{B}\left(\mathrm{C}_{6} \mathrm{~F}_{5}\right)_{3}$ catalyst with $\left(\mathrm{C}_{6} \mathrm{~F}_{5}\right)_{3} \mathrm{~B}\left(\mathrm{OH}_{2}\right)$ aimed at understanding the effect of the moisture stable $\left(\mathrm{C}_{6} \mathrm{~F}_{5}\right)_{3} \mathrm{~B}\left(\mathrm{OH}_{2}\right)$ catalyst on the selectivity, the recyclability and the mechanism of siloxane formation.

\section{MATERIALS AND METHODS}

All reactions and manipulations were performed under a nitrogen atmosphere in an MBraun Unilab 1200/780 glovebox or using conventional Schlenk techniques, unless otherwise specified. Dry solvents were obtained using a solvent purification system. Reagents were purchased from Sigma-Aldrich, AK Scientific, Arcos and TCI and used as received. $\left(\mathrm{C}_{6} \mathrm{~F}_{5}\right)_{3} \mathrm{~B}\left(\mathrm{OH}_{2}\right)$ (Beringhelli et al., 2001) was made by adding a stoichiometric amount of $\mathrm{H}_{2} \mathrm{O}$ to $\mathrm{B}\left(\mathrm{C}_{6} \mathrm{~F}_{5}\right)_{3}$ followed by purification by sublimation. ${ }^{1} \mathrm{H},{ }^{13} \mathrm{C}$, and ${ }^{29} \mathrm{Si}$ NMR spectra were recorded on a Bruker DPX-400 (400MHz) spectrometer. Chemical shifts for protons are reported in parts per million (ppm) downfield from tetramethylsilane and are referenced to residual protium in the NMR solvent (e.g., $\mathrm{CHCl}_{3}=7.26 \mathrm{ppm}$ ). Chemical shifts for carbon are reported in ppm downfield from $\mathrm{CDCl}_{3}(77.3 \mathrm{ppm})$.
Chemical shifts for silicon are reported in ppm downfield to the silicon resonance of tetramethylsilane (TMS $\delta 0.0$ ). The silicon NMR resonances were determined with a DEPT pulse sequence. Data are represented as follows: chemical shift, multiplicity (app $=$ apparent, $\mathrm{br}=$ broad, $\mathrm{s}=$ singlet, $\mathrm{d}=$ doublet, $\mathrm{t}=$ triplet, $\mathrm{q}=$ quartet, $\mathrm{m}=$ multiplet), coupling constants in Hertz $(\mathrm{Hz})$, and integration. High resolution mass spectrometry measurements were made on a Bruker microTOF-QII mass spectrometer, equipped with a KD Scientific syringe pump, in positive ion ESI mode. Hard ionization mass spectrometry analysis was done on Agilent 7890A GC + 5975C EI-MS with Agilent auto-sampler. $\mathrm{X}$-ray diffraction analysis of single crystals of $\mathbf{7 a}$ and $\mathbf{8 a}$ were performed on a Rigaku Oxford Diffraction XtaLAB-Synergy-S single crystal diffractometer with a PILATUS $200 \mathrm{~K}$ hybrid pixel array detector using $\mathrm{Cu} \mathrm{K \alpha}$ radiation (Supplementary Table 1). The data was processed with the SHELX2016 (Sheldrick, 2015) and Olex2 (Dolomanov et al., 2009) software packages. All nonhydrogen atoms were refined anisotropically. Hydrogen atoms were inserted at calculated positions and refined with a riding model or without restrictions. 8a was refined on a HKL5 dataset extracted from PLATON (Spek, 2003). Mercury 4.2.0 (Macrae et al., 2006) was used to visualize the molecular structures.

\section{Intermolecular Reactions}

\section{Synthesis of Tertiary Disiloxanes, 3a-3c}

$\mathrm{Et}_{3} \mathrm{SiOEt}_{3}$ (3a) and $\mathrm{PhMe}_{2} \mathrm{SiOSiMe}_{2} \mathrm{Ph}$ (3b)

To a mixture of hydrosilane $\left(\mathrm{Et}_{3} \mathrm{SiH}, \mathbf{1 a}, 5.0 \mathrm{mmol}, 0.80 \mathrm{~mL}\right.$ or $\mathrm{PhMe}_{2} \mathrm{SiH}, \mathbf{1 b}, 5.0 \mathrm{mmol}, 0.77 \mathrm{~mL}$ ) and $0.1-5.0 \mathrm{~mol} \%$ $\left(\mathrm{C}_{6} \mathrm{~F}_{5}\right)_{3} \mathrm{~B}\left(\mathrm{OH}_{2}\right)$, was added $\mathrm{H}_{2} \mathrm{O}(2.5 \mathrm{mmol}, 0.050 \mathrm{~mL})$ while stirring at room temperature $\left(22^{\circ} \mathrm{C}\right)$. The reaction was monitored using ${ }^{1} \mathrm{H}$ and ${ }^{29} \mathrm{Si}\left\{{ }^{1} \mathrm{H}\right\}$ NMR spectroscopy at specific time interval using an insert containing deuterated solvent. Yield: $3 \mathbf{a}$ : $70.6 \%$, 3b: $94.0 \%$.

\section{$3 a$ (Sridhar et al., 2009; Jorapur and Shimada, 2012)}

${ }^{1} \mathrm{H}$ NMR $\left(400 \mathrm{MHz} \mathrm{CDCl}_{3}\right): \delta$ 0.95-0.91 (t, $\left.\mathrm{CH}_{3}, 6 \mathrm{H}\right), \delta 0.55-$ $0.49\left(\mathrm{q}, \mathrm{CH}_{2}, 4 \mathrm{H}\right) .{ }^{13} \mathrm{C}\left\{{ }^{1} \mathrm{H}\right\} \operatorname{NMR}\left(100.6 \mathrm{MHz}, \mathrm{CDCl}_{3}\right): \delta 6.7$ (s, $\left.\mathrm{CH}_{2}\right), \delta 6.4\left(\mathrm{~s}, \mathrm{CH}_{3}\right) .{ }^{29} \mathrm{Si}\left\{{ }^{1} \mathrm{H}\right\} \mathrm{NMR}\left(79.5 \mathrm{MHz} \mathrm{CDCl}_{3}\right): \delta 8.9$ ppm (s). GC-MS: cal'd: $246.1835 \mathrm{~m} / z$; observed $246.1900 \mathrm{~m} / z$.

$3 b$ (Jorapur and Shimada, 2012; Sawama et al., 2016)

${ }^{1} \mathrm{H}$ NMR (400 $\mathrm{MHz} \mathrm{CDCl}_{3}$ ): $\delta$ 7.57-7.36 (m, Ph, 10H), $\delta 0.35$ (s, $\left.\mathrm{CH}_{3}, 12 \mathrm{H}\right) .{ }^{13} \mathrm{C}\left\{{ }^{1} \mathrm{H}\right\} \mathrm{NMR}\left(100.6 \mathrm{MHz}, \mathrm{CDCl}_{3}\right): \delta 139.8, \delta$ $133.0, \delta 129.4, \delta 127.7, \delta 0.85\left(\mathrm{~s}, \mathrm{CH}_{3}\right) .{ }^{29} \mathrm{Si}\left\{{ }^{1} \mathrm{H}\right\} \mathrm{NMR}(79.5 \mathrm{MHz}$, $\left.\mathrm{CDCl}_{3}\right): \delta 0.01 \mathrm{ppm}(\mathrm{s})$. HRMS-ESI: $\left[\mathrm{C}_{16} \mathrm{H}_{22} \mathrm{OSi}_{2} \mathrm{Na}\right]^{+}=\mathrm{cal}^{\prime} \mathrm{d}$ : $309.1101 \mathrm{~m} / \mathrm{z}$; observed $309.1091 \mathrm{~m} / \mathrm{z}$.

\section{$\mathrm{Ph}_{3} \mathrm{SiOSiPh}_{3}, 3 \mathrm{c}$}

To a mixture of $\mathrm{Ph}_{3} \mathrm{SiH}$ (1c; $2.0 \mathrm{mmol}, 0.26 \mathrm{~g}$ ) and 0.1-5.0 mol\% $\left(\mathrm{C}_{6} \mathrm{~F}_{5}\right)_{3} \mathrm{~B}\left(\mathrm{OH}_{2}\right)$ dissolved in $0.50 \mathrm{~mL}$ toluene- $\mathrm{d}_{8}$, was added $\mathrm{H}_{2} \mathrm{O}(1.0 \mathrm{mmol}, 0.02 \mathrm{~mL})$ while stirring at room temperature $\left(22^{\circ} \mathrm{C}\right)$. The reaction was monitored using ${ }^{1} \mathrm{H}$ and ${ }^{29} \mathrm{Si}\left\{{ }^{1} \mathrm{H}\right\} \mathrm{NMR}$ spectroscopy at specific time interval. Yield: $98.0 \%$.

\section{$3 c$ (Jorapur and Shimada, 2012)}

${ }^{1} \mathrm{H}$ NMR (400 MHz $\left.\mathrm{CDCl}_{3}\right): \delta 7.49-7.24(\mathrm{~m}, \mathrm{Ph}, 30 \mathrm{H}) .{ }^{13} \mathrm{C}\left\{{ }^{1} \mathrm{H}\right\}$ NMR (100.6 MHz, $\left.\mathrm{CDCl}_{3}\right): \delta 135.5, \delta 135.2, \delta$ 129.8, $\delta$ 127.7. 
${ }^{29} \mathrm{Si}\left\{{ }^{1} \mathrm{H}\right\}$ NMR $\left(79.5 \mathrm{MHz}, \mathrm{CDCl}_{3}\right): \delta-18.6 \mathrm{ppm}$ (s). HRMS-ESI: $\left[\mathrm{C}_{36} \mathrm{H}_{30} \mathrm{OSi}_{2} \mathrm{Na}\right]^{+}$cal'd: $557.1733 \mathrm{~m} / z$; observed $557.1701 \mathrm{~m} / \mathrm{z}$.

\section{Synthesis of Secondary Oligosiloxanes, (Cyclo) 3d-3f, (Cyclo) 4e-4f, 5e}

To a mixture of $4.0 \mathrm{mmol}$ hydrosilane $\left(0.52 \mathrm{~mL} \mathrm{Et}_{2} \mathrm{SiH}_{2}\right.$, 1d; $0.55 \mathrm{~mL} \mathrm{PhMeSiH} 2, \mathbf{1 e} ; 0.76 \mathrm{~mL} \mathrm{Ph}_{2} \mathrm{SiH}_{2}$, 1f) and $0.1-$ $5.0 \mathrm{~mol} \%\left(\mathrm{C}_{6} \mathrm{~F}_{5}\right)_{3} \mathrm{~B}\left(\mathrm{OH}_{2}\right)$, was added $2.0 \mathrm{mmol}, 0.04 \mathrm{~mL} \mathrm{H} \mathrm{H}_{2} \mathrm{O}$ while stirring at room temperature $\left(22^{\circ} \mathrm{C}\right)$. The reaction was monitored using ESI-MS at specific time interval. All products were filtered through Florisil to remove the catalyst using $n$ pentane or hexanes $(10 \mathrm{ml})$ as eluent. ESI-MS: 3d (trimer): $\left[\mathrm{C}_{14} \mathrm{H}_{36} \mathrm{O}_{4} \mathrm{Si}_{3} \mathrm{Na}\right]^{+}$cal'd: $375.1819 \mathrm{~m} / z$; observed $375.1812 \mathrm{~m} / z$, cyclo-3d (cyclic trimer): $\left[\mathrm{C}_{13} \mathrm{H}_{33} \mathrm{O}_{3} \mathrm{Si}_{3} \mathrm{Na}\right]^{+}$cal'd: 321.1737 $m / z$; observed $321.1731 \mathrm{~m} / z$, 3 e (trimer): $\left[\mathrm{C}_{23} \mathrm{H}_{30} \mathrm{O}_{4} \mathrm{Si}_{3} \mathrm{Na}\right]^{+}$ cal'd: $477.1350 \mathrm{~m} / z$; observed $477.1337 \mathrm{~m} / z$, 4e (tetramer): $\left[\mathrm{C}_{28} \mathrm{H}_{34} \mathrm{O}_{5} \mathrm{Si}_{4} \mathrm{Na}\right]^{+}$cal'd: $585.1381 \mathrm{~m} / z$; observed $585.1357 \mathrm{~m} / z$, 5e (pentamer): $\left[\mathrm{C}_{35} \mathrm{H}_{42} \mathrm{O}_{6} \mathrm{Si}_{5} \mathrm{Na}\right]^{+}$cal'd: $721.1725 \mathrm{~m} / z$; observed $721.1657 \mathrm{~m} / z$, cyclo-3f (cyclic trimer): $\left[\mathrm{C}_{36} \mathrm{H}_{30} \mathrm{O}_{3} \mathrm{Si}_{3} \mathrm{Na}\right]^{+}$cal'd: $617.1400 \mathrm{~m} / z$; observed $617.1356 \mathrm{~m} / z$, cyclo-4f (cyclic tetramer): $\left[\mathrm{C}_{48} \mathrm{H}_{40} \mathrm{O}_{4} \mathrm{Si}_{4} \mathrm{Na}\right]^{+}$cal'd: $815.1901 \mathrm{~m} / z$; observed $815.1837 \mathrm{~m} / \mathrm{z}$.

\section{Intramolecular Reactions}

\section{Synthesis of Disilyl Precursors, 7a-7c}

To an oven dried two neck round bottom flask purged with nitrogen was added magnesium turnings $(12.0 \mathrm{mmol}, 0.29 \mathrm{~g})$, dry THF $(5 \mathrm{~mL})$ and diphenylchlorosilane $(7 \mathbf{a} ; 12.0 \mathrm{mmol}, 2.3 \mathrm{~mL})$ or dimethylchlorosilane $(7 \mathbf{b}, 7 \mathrm{c} ; 12.0 \mathrm{mmol}, 1.3 \mathrm{~mL})$. To this suspension was added 2-bromobenzylbromide $(6 \mathbf{6 a} ; 3.0 \mathrm{mmol}$, $0.75 \mathrm{~g}$ ) or $\alpha, \alpha^{\prime}$-dibromo-o-xylene ( $\left.6 \mathbf{b} ; 3.0 \mathrm{mmol}, 0.79 \mathrm{~g}\right)$ dissolved in dry THF $(10 \mathrm{~mL})$ dropwise over a period of $15 \mathrm{~min}$. The mixture was refluxed for $1 \mathrm{~h}$ and then stirred at $22^{\circ} \mathrm{C}$ overnight. The reaction mixture was quenched with saturated solution of $\mathrm{NaHCO}_{3}(5 \mathrm{~mL})$ and the aqueous layer was extracted with diethyl ether $(3 \times 10 \mathrm{~mL})$. All the organic layers were combined and dried over $\mathrm{Na}_{2} \mathrm{SO}_{4}$. The crude product was obtained upon removal of solvents under vacuum.

\section{(2-(diphenylsilyl)benzyl)diphenylsilane (7a)}

The crude product was dissolved in $n$-pentane $(20 \mathrm{~mL})$ and the mixture was stored at $-20^{\circ} \mathrm{C}$ overnight. Colorless crystals were filtered off and were washed with cold pentane $(2 \times 5 \mathrm{~mL})$ to obtain the pure product in $72.3 \%$ yield.

${ }^{1} \mathrm{H}$ NMR $\left(400 \mathrm{MHz} \mathrm{CDCl}_{3}\right): \delta 7.45-6.97(\mathrm{~m}, \mathrm{Ph}, 24 \mathrm{H}), \delta 5.53$ (s, $\mathrm{SiH}, 1 \mathrm{H}), \delta 4.8$ (t, $\mathrm{SiH}, 1 \mathrm{H}), 2.8\left(\mathrm{~d}, \mathrm{CH}_{2}, 2 \mathrm{H}\right) .{ }^{13} \mathrm{C}\left\{{ }^{1} \mathrm{H}\right\} \mathrm{NMR}$ $\left(100.6 \mathrm{MHz}, \mathrm{CDCl}_{3}\right): \delta 145.67, \delta 137.16, \delta 135.95, \delta 135.38, \delta$ $134.32, \delta 133.58, \delta 133.39, \delta 131.36, \delta 129.98, \delta 129.66, \delta 128.01$, $\delta 127.89, \delta 124.28, \delta 23.06 .{ }^{29} \mathrm{Si}\left\{{ }^{1} \mathrm{H}\right\} \mathrm{NMR}\left(79.5 \mathrm{MHz}, \mathrm{CDCl}_{3}\right)$ : $\delta-13.70, \delta-22.48$ ppm. HRMS-ESI: $\left[\mathrm{C}_{31} \mathrm{H}_{28} \mathrm{Si}_{2} \mathrm{Na}\right]^{+}$cal'd: $479.1626 \mathrm{~m} / \mathrm{z}$; observed: $479.1615 \mathrm{~m} / \mathrm{z}$.

\section{(2-(dimethylsilyl)benzyl)diphenylsilane (7b)}

The crude product was purified over silica gel column chromatography using hexanes as the eluent and was obtained as a colorless oil in $80.8 \%$ yield.

${ }^{1} \mathrm{H}$ NMR (400 MHz CDCl $): \delta 7.45-7.05(\mathrm{~m}, \mathrm{Ph}, 4 \mathrm{H}), \delta 4.5$ (sep, $\mathrm{SiH}, 1 \mathrm{H}$ ), $\delta 3.9$ (sep, $\mathrm{SiH}, 1 \mathrm{H}$ ), $2.3\left(\mathrm{~d}, \mathrm{CH}_{2}, 2 \mathrm{H}\right), \delta 0.3$ (d, $\left.\mathrm{CH}_{3}, 6 \mathrm{H}\right), \delta 0.1\left(\mathrm{~d}, \mathrm{CH}_{3}, 6 \mathrm{H}\right) .{ }^{13} \mathrm{C}\left\{{ }^{1} \mathrm{H}\right\} \mathrm{NMR}(100.6 \mathrm{MHz}$, $\left.\mathrm{CDCl}_{3}\right): \delta 146.04, \delta 134.77, \delta 129.34, \delta 128.32, \delta 123.85, \delta 24.39$, $\delta-3.06, \delta-4.26 .{ }^{29} \mathrm{Si}\left\{{ }^{1} \mathrm{H}\right\} \operatorname{NMR}\left(79.5 \mathrm{MHz}, \mathrm{CDCl}_{3}\right): \delta-11.04$, $\delta-21.63 \mathrm{ppm}$. HRMS-ESI: $\left[\mathrm{C}_{11} \mathrm{H}_{20} \mathrm{Si}_{2} \mathrm{H}\right]^{+}$cal'd: $209.1181 \mathrm{~m} / z$; observed: $209.1171 \mathrm{~m} / \mathrm{z}$.

\section{1,2-bis((dimethylsilyl)methyl)benzene (7c)}

The crude product was purified over silica gel column chromatography using hexanes as the eluent and was obtained as colorless oil in $52.5 \%$ yield.

${ }^{1} \mathrm{H}$ NMR (400 MHz CDCl $): \delta 6.99$ (s, Ph, 4H), $\delta 4.0$ (sep, $\mathrm{SiH}$, $1 \mathrm{H}), \delta 2.1\left(\mathrm{~d}, \mathrm{CH}_{2}, 2 \mathrm{H}\right), \delta 0.1\left(\mathrm{~d}, \mathrm{CH}_{3}, 12 \mathrm{H}\right) .{ }^{13} \mathrm{C}\left\{{ }^{1} \mathrm{H}\right\} \operatorname{NMR}(100.6$ $\left.\mathrm{MHz}, \mathrm{CDCl}_{3}\right): \delta 136.71, \delta 129.19, \delta 124.47, \delta 21.61, \delta-4.21$. ${ }^{29} \mathrm{Si}\left\{{ }^{1} \mathrm{H}\right\} \mathrm{NMR}\left(79.5 \mathrm{MHz}, \mathrm{CDCl}_{3}\right): \delta-13.28$ ppm. GC-MS: cal'd: $222.1260 \mathrm{~m} / z$; observed: $222.1000 \mathrm{~m} / \mathrm{z}$.

\section{Synthesis of Bridged Siloxanes, 8a-8c}

1,1,3,3-tetraphenyl-3,4-dihydro-1H-2,1,3-

benzoxadisiline ( $8 a$ )

To a round bottom flask was added $7 \mathbf{a}(1.0 \mathrm{mmol}, 0.45 \mathrm{~g})$ and $5.0 \mathrm{~mol} \%\left(\mathrm{C}_{6} \mathrm{~F}_{5}\right)_{3} \mathrm{~B}\left(\mathrm{OH}_{2}\right)$. The solids were dissolved in toluene $(10 \mathrm{~mL})$ and the reaction mixture was stirred at $90^{\circ} \mathrm{C}$ for $24 \mathrm{~h}$. Toluene was removed under vacuum and the crude product was dissolved in hexanes $(10 \mathrm{~mL})$ which was then filtered through a Florisil pad with hexanes as eluent. Upon removal of volatiles the product was obtained as white solids. After recrystallization in ethyl acetate a pure crystalline product with $45.2 \%$ yield was obtained.

${ }^{1} \mathrm{H}$ NMR (400 MHz $\left.\mathrm{CDCl}_{3}\right): \delta$ 7.57-7.06 (m, Ph, 24H), $\delta 2.64$ (s, $\left.\mathrm{CH}_{2}, 2 \mathrm{H}\right) \cdot{ }^{13} \mathrm{C}\left\{{ }^{1} \mathrm{H}\right\} \mathrm{NMR}\left(100.6 \mathrm{MHz}, \mathrm{CDCl}_{3}\right): \delta 145.04, \delta$ $135.42, \delta 135.14, \delta 134.97, \delta 134.31, \delta 130.56, \delta 130.48, \delta 130.13$, $\delta 130.02, \delta 127.86, \delta 124.63, \delta 23.66 .{ }^{29} \mathrm{Si}\left\{{ }^{1} \mathrm{H}\right\}$ NMR $(79.5 \mathrm{MHz}$, $\left.\mathrm{CDCl}_{3}\right): \delta-9.91,-14.11$ ppm. HRMS-ESI: $\left[\mathrm{C}_{31} \mathrm{H}_{26} \mathrm{OSi}_{2} \mathrm{Na}\right]^{+}$ cal'd: $493.1419 \mathrm{~m} / z$; observed: $493.1421 \mathrm{~m} / \mathrm{z}$.

\section{1,1,3,3-tetramethyl-3,4-dihydro-1H-2,1,3- \\ benzoxadisiline $(8 b)$}

To a vial was added $1.0 \mathrm{~mol} \%\left(\mathrm{C}_{6} \mathrm{~F}_{5}\right)_{3} \mathrm{~B}\left(\mathrm{OH}_{2}\right), 0.5 \mathrm{~mL}$ toluene and $7 \mathbf{b}(1.0 \mathrm{mmol}, 0.21 \mathrm{~g})$. The reaction mixture was stirred for $3 \mathrm{~h}$ at $22^{\circ} \mathrm{C}$. Toluene was then removed under reduced pressure and hexanes $(3 \mathrm{~mL})$ was added to the mixture. Upon Florisil filtration with hexanes as eluent and removal of volatiles the product was obtained as clear oil with $61.8 \%$ yield.

${ }^{1} \mathrm{H}$ NMR $\left(400 \mathrm{MHz} \mathrm{CDCl}_{3}\right): \delta$ 7.40-7.12 (m, Ph, 4H), $\delta 2.19$ (s, $\left.\mathrm{CH}_{2}, 2 \mathrm{H}\right), \delta 0.38\left(\mathrm{~s}, \mathrm{CH}_{3}, 6 \mathrm{H}\right), \delta 0.16\left(\mathrm{~s}, \mathrm{CH}_{3}, 6 \mathrm{H}\right) .{ }^{29} \mathrm{Si}\left\{{ }^{1} \mathrm{H}\right\}$ NMR $\left(79.5 \mathrm{MHz}, \mathrm{CDCl}_{3}\right): \delta 10.85, \delta 3.66 \mathrm{ppm}$. HRMS-ESI: $\left[\mathrm{C}_{11} \mathrm{H}_{18} \mathrm{OSi}_{2} \mathrm{H}\right]^{+}$cal'd: $223.0974 \mathrm{~m} / z$; observed: $223.0925 \mathrm{~m} / \mathrm{z}$.

\section{2,2,4,4-tetramethyl-1,2,4,5-tetrahydrobenzoxadisilepine (8c)}

To a vial was added $1.0 \mathrm{~mol} \%\left(\mathrm{C}_{6} \mathrm{~F}_{5}\right)_{3} \mathrm{~B}\left(\mathrm{OH}_{2}\right), 0.5 \mathrm{~mL}$ toluene and $7 \mathrm{c}(1.0 \mathrm{mmol}, 0.22 \mathrm{~g})$. The reaction mixture was stirred for $3 \mathrm{~h}$ at $22^{\circ} \mathrm{C}$. Toluene was then removed under reduced pressure and hexanes $(3 \mathrm{~mL})$ was added to the mixture. Upon Florisil filtration with hexanes as eluent and removal of volatiles the product was obtained as clear oil with $30.6 \%$ yield.

${ }^{1} \mathrm{H}$ NMR $\left(400 \mathrm{MHz} \mathrm{CDCl}_{3}\right): \delta 7.03-6.95(\mathrm{~m}, \mathrm{Ph}, 4 \mathrm{H}), \delta 2.16$ (s, $\left.\mathrm{CH}_{2}, 2 \mathrm{H}\right), \delta 0.07\left(\mathrm{~s}, \mathrm{CH}_{3}, 12 \mathrm{H}\right) .{ }^{13} \mathrm{C}\left\{{ }^{1} \mathrm{H}\right\} \mathrm{NMR}(100.6 \mathrm{MHz}$, 
$\left.\mathrm{CDCl}_{3}\right): \delta 137.38, \delta 129.35, \delta 125.04, \delta 27.48, \delta 0.0 .{ }^{29} \mathrm{Si}\left\{{ }^{1} \mathrm{H}\right\} \mathrm{NMR}$ $\left(79.5 \mathrm{MHz}, \mathrm{CDCl}_{3}\right): \delta 7.23 \mathrm{ppm}$. HRMS-ESI: $\left[\mathrm{C}_{12} \mathrm{H}_{20} \mathrm{OSi}_{2} \mathrm{H}\right]^{+}$ cal'd: $237.1130 \mathrm{~m} / z$; observed: $237.1123 \mathrm{~m} / \mathrm{z}$.

\section{Cross-Condensation Reactions}

\section{$1: 1$ reaction of $1 a$ and $1 c$}

To a mixture of 1 equiv. 1a, 1 equiv. $1 \mathrm{c}$ and $5.0 \mathrm{~mol} \%$ $\left(\mathrm{C}_{6} \mathrm{~F}_{5}\right)_{3} \mathrm{~B}\left(\mathrm{OH}_{2}\right)$ dissolved in $0.5 \mathrm{~mL} \mathrm{C}_{6} \mathrm{D}_{6}$, was added $1.0 \mathrm{mmol}$, $0.02 \mathrm{~mL} \mathrm{H}_{2} \mathrm{O}$. The reaction was stirred for $5 \mathrm{~min}$ at $22^{\circ} \mathrm{C}$ and was analyzed by ${ }^{1} \mathrm{H}$ and ${ }^{29} \mathrm{Si}\left\{{ }^{1} \mathrm{H}\right\}$ NMR spectroscopy.

\section{1:1 reaction of $2 a$ and $1 b$}

A mixture of 1 equiv. 2a, 1 equiv. $1 \mathbf{b}$ and $5.0 \mathrm{~mol} \%$ $\left(\mathrm{C}_{6} \mathrm{~F}_{5}\right)_{3} \mathrm{~B}\left(\mathrm{OH}_{2}\right)$ was stirred for $1 \mathrm{~h}$ at $22^{\circ} \mathrm{C}$ and was analyzed by ${ }^{1} \mathrm{H}$ and ${ }^{29} \mathrm{Si}\left\{{ }^{1} \mathrm{H}\right\}$ NMR spectroscopy.

\section{$1: 1$ reaction of $1 b$ and $2 b$}

A mixture of 1 equiv. $1 \mathbf{b}, 1$ equiv. $2 \mathbf{b}$ and $5.0 \mathrm{~mol} \%$ $\left(\mathrm{C}_{6} \mathrm{~F}_{5}\right)_{3} \mathrm{~B}\left(\mathrm{OH}_{2}\right)$ was stirred for $5 \mathrm{~min}$ at $22^{\circ} \mathrm{C}$ and was analyzed by ${ }^{1} \mathrm{H}$ and ${ }^{29} \mathrm{Si}\left\{{ }^{1} \mathrm{H}\right\}$ NMR spectroscopy.

\section{Control Reactions}

A mixture of silanol $\left(\mathrm{Et}_{3} \mathrm{SiOH}, 2 \mathrm{a}, 2.6 \mathrm{mmol}, 0.40 \mathrm{~mL}\right.$ or $\mathrm{PhMe}_{2} \mathrm{SiOH}, 2$ b, $2.6 \mathrm{mmol}, 0.40 \mathrm{~mL}$ ) and $0.1-0.5 \mathrm{~mol} \%$ $\left(\mathrm{C}_{6} \mathrm{~F}_{5}\right)_{3} \mathrm{~B}\left(\mathrm{OH}_{2}\right)$ was stirred and allowed to react at room temperature $\left(22^{\circ} \mathrm{C}\right)$. The reaction was monitored using ${ }^{1} \mathrm{H}$ and ${ }^{29} \mathrm{Si}\left\{{ }^{1} \mathrm{H}\right\}$ NMR spectroscopy at a specific time interval.

\section{Catalyst Recycling Studies}

\section{3a}

To 0.1-5.0 mol\% $\left(\mathrm{C}_{6} \mathrm{~F}_{5}\right)_{3} \mathrm{~B}\left(\mathrm{OH}_{2}\right)$ was added $5.0 \mathrm{mmol}, 0.80 \mathrm{~mL}$ $\mathrm{Et}_{3} \mathrm{SiH}$ while stirring at room temperature $\left(22^{\circ} \mathrm{C}\right)$. The reaction was monitored using ${ }^{1} \mathrm{H}$ NMR after 1 and $3 \mathrm{~h}$. At the end of the $3 \mathrm{~h}$ period, each product from different catalyst loading was isolated by extraction with pentane while recovering back the $\left(\mathrm{C}_{6} \mathrm{~F}_{5}\right)_{3} \mathrm{~B}\left(\mathrm{OH}_{2}\right)$ catalyst used. The recovered catalyst at $1.0 \mathrm{~mol} \%$ loading was recycled and re-used 4 times to give a total of 5 cycles and 5 isolated yields for $\mathrm{Et}_{3} \mathrm{SiOSiEt}_{3}$.

\section{$3 b$}

To 0.1-5.0 mol\% $\left(\mathrm{C}_{6} \mathrm{~F}_{5}\right)_{3} \mathrm{~B}\left(\mathrm{OH}_{2}\right)$ was added $2.0 \mathrm{mmol}, 0.31 \mathrm{~mL}$ $\mathrm{PhMe}_{2} \mathrm{SiH}$ while stirring at room temperature $\left(22^{\circ} \mathrm{C}\right)$. The reaction was monitored using ${ }^{1} \mathrm{H}$ NMR after $1 \mathrm{~h}$. At the end of the $1 \mathrm{~h}$ period, each product from different catalyst loading was isolated by extraction with pentane. At $1.0 \mathrm{~mol} \%$ catalyst loading, another $0.31 \mathrm{~mL}$ ( $2.0 \mathrm{mmol}$ ) of $\mathrm{PhMe}_{2} \mathrm{SiH}$ was added to the same vial. This procedure was done 4 times at $1 \mathrm{~h}$ intervals. The reported \% yield at $1.0 \mathrm{~mol} \%$ catalyst loading was the average of 5 cycles.

\section{$3 c$}

To 0.1-5.0 mol\% $\left(\mathrm{C}_{6} \mathrm{~F}_{5}\right)_{3} \mathrm{~B}\left(\mathrm{OH}_{2}\right)$ was added $1.0 \mathrm{mmol}, 0.26 \mathrm{~g}$ $\mathrm{Ph}_{3} \mathrm{SiH}$, dissolved in $0.50 \mathrm{~mL}$ toluene, while stirring at room temperature $\left(22^{\circ} \mathrm{C}\right)$. The reaction was monitored using ${ }^{1} \mathrm{H}$ NMR after 1 and $2 \mathrm{~h}$. At the end of the $2 \mathrm{~h}$ period, each product from different catalyst loading was isolated by extraction with dichloromethane $(5 \mathrm{~mL})$. At $1.0 \mathrm{~mol} \%$ catalyst loading, another $0.26 \mathrm{~g}(1.0 \mathrm{mmol})$ of $\mathrm{Ph}_{3} \mathrm{SiH}$ dissolved in $0.50 \mathrm{~mL}$ toluene was added to the same vial. This procedure was done 4 times at a $2 \mathrm{~h}$ intervals. The reported $\%$ yield at $1.0 \mathrm{~mol} \%$ catalyst loading was the average of 5 cycles.

\section{RESULTS AND DISCUSSION}

\section{Intermolecular Synthesis of Oligosiloxanes Using a $\left(\mathrm{C}_{6} \mathrm{~F}_{5}\right)_{3} \mathrm{~B}\left(\mathrm{OH}_{2}\right)$ Catalyst}

Three different types of tertiary hydrosilanes $\left(\mathrm{Et}_{3} \mathrm{SiH}, \mathbf{1 a}\right.$; $\mathrm{PhMe}_{2} \mathrm{SiH}, \mathbf{1 b}$; and $\left.\mathrm{Ph}_{3} \mathrm{SiH}, \mathbf{1 c}\right)$ were reacted with varying equivalents of $\mathrm{H}_{2} \mathrm{O}(0.0-1.0)$ and varying concentrations of catalyst $(0.1-10.0 \mathrm{~mol} \%)$, at $22^{\circ} \mathrm{C}$ to yield the corresponding disiloxane (3a-c; Scheme 2). For each completed reaction, the catalyst was removed by Florisil filtration. For $\mathbf{1 a}$ and $\mathbf{1 b}$, the siloxane product was isolated by dissolving the reaction mixture in $n$-pentane to selectively precipitate out the $\left(\mathrm{C}_{6} \mathrm{~F}_{5}\right)_{3} \mathrm{~B}\left(\mathrm{OH}_{2}\right)$ catalyst. 1c is a solid so the catalytic reactions were enabled by the addition of minimum amount of dry toluene $(\sim 1 \mathrm{~mL})$. The disiloxane products formed $(\mathbf{3 a}-\mathbf{3 c})$ from this synthetic route were isolated and confirmed by several characterization techniques in conjunction (Supplementary Figures 1-28) (Jorapur and Shimada, 2012). Generally, the complete conversion to disiloxane is much slower in the absence of $\mathrm{H}_{2} \mathrm{O}$ and no reaction can be observed in the absence of the catalyst (Table 1 ). The transformation of neat $\mathbf{1} \mathbf{b}$ to the corresponding disiloxane appeared to be the fastest and most facile at $0.1 \mathrm{~mol} \%$ catalyst loading. This may be attributed to the fact that $\left(\mathrm{C}_{6} \mathrm{~F}_{5}\right)_{3} \mathrm{~B}\left(\mathrm{OH}_{2}\right)$ is quite soluble in $\mathbf{1 b}$.

The reaction of 1a was slow at a low catalyst loading, $0.1 \mathrm{~mol} \%\left(\mathrm{C}_{6} \mathrm{~F}_{5}\right)_{3} \mathrm{~B}\left(\mathrm{OH}_{2}\right)$, in the presence of 0.5 eq $\mathrm{H}_{2} \mathrm{O}$. However, this allowed the for the detection of the silanol intermediate, $\mathrm{Et}_{3} \mathrm{SiOH}, \mathbf{2 a}$, along with the formation of the disiloxane, $\mathrm{Et}_{3} \mathrm{SiOSiEt}_{3}, \mathbf{3 a}$ (Supplementary Figures 6, 7). After $3 \mathrm{~h}$, the formation of both $\mathbf{2 a}\left(\delta_{\mathrm{Si}}=19.8 \mathrm{ppm}\right)$ and $\mathbf{3 a}\left(\delta_{\mathrm{Si}}\right.$ $=8.9 \mathrm{ppm})$ was more evident with a significant amount of unreacted 1a $\left(\delta_{\mathrm{Si}}=0.01 \mathrm{ppm}\right)$. By contrast, the reaction was almost complete after $1 \mathrm{~h}$ when the catalyst loading was increased to $1.0 \mathrm{~mol} \%\left(\mathrm{C}_{6} \mathrm{~F}_{5}\right)_{3} \mathrm{~B}\left(\mathrm{OH}_{2}\right)$, with $>99 \%$ conversion and the 3a as the major product. There was no significant change observed when the same reaction was left to react further for $24 \mathrm{~h}$ (Supplementary Figures 8, 9). When the catalyst loading was further increased to $5.0 \mathrm{~mol} \%\left(\mathrm{C}_{6} \mathrm{~F}_{5}\right)_{3} \mathrm{~B}\left(\mathrm{OH}_{2}\right)$ the results were the same as those found at the $1.0 \mathrm{~mol} \%$ catalyst loading. As suggested by the Piers-Rubinsztajn mechanism, the condensation of silanols to form oligo- or polysiloxanes occurs at relatively low catalyst concentration (Brook, 2018). A control reaction wherein 1a was reacted with 1.0 eq $\mathrm{H}_{2} \mathrm{O}$ in the absence of the catalyst gave no reaction, showing only the presence of unreacted 1a by NMR spectroscopy. Similarly, no reaction was observed when 2a was reacted with an equivalent of $\mathrm{H}_{2} \mathrm{O}$ without a catalyst. These studies prove that both the conversion of 1a to $2 \mathbf{a}$ and the condensation step to $\mathbf{3 a}$ require a catalyst (Supplementary Figures 10, 11).

Staring from a low catalyst loading of $0.1 \mathrm{~mol} \%$ $\left(\mathrm{C}_{6} \mathrm{~F}_{5}\right)_{3} \mathrm{~B}\left(\mathrm{OH}_{2}\right)$ in the presence of 0.5 eq $\mathrm{H}_{2} \mathrm{O}$, the conversion of $\mathrm{PhMe}_{2} \mathrm{SiH}, \mathbf{1 b}$, to the corresponding disiloxane, $\mathbf{3 b}\left(\delta_{\mathrm{Si}}\right.$ 


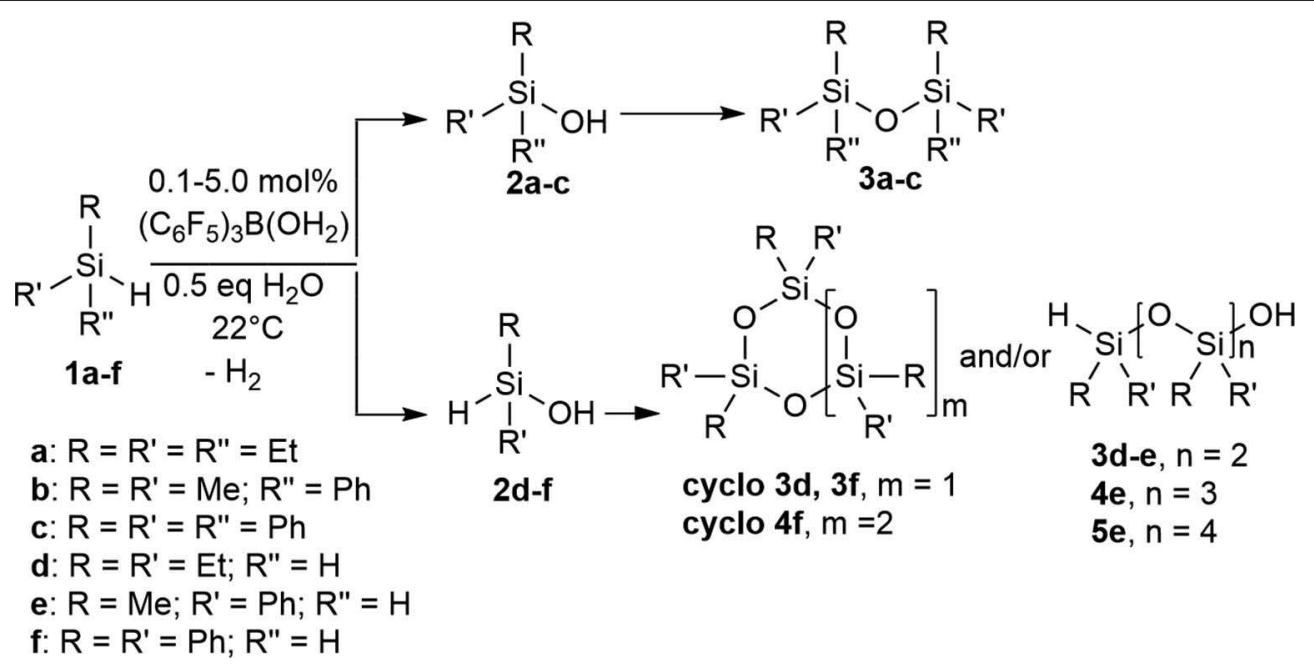

SCHEME 2 | Intermolecular synthesis of siloxanes using a $\left(\mathrm{C}_{6} \mathrm{~F}_{5}\right)_{3} \mathrm{~B}\left(\mathrm{OH}_{2}\right)$ catalyst.

TABLE 1 | Scope of substrates and products in the synthesis of disiloxanes, $\mathbf{3 a - 3 c .}$

\begin{tabular}{|c|c|c|c|c|c|c|}
\hline Substrate & Catalyst, mol \% & $\begin{array}{l}\mathrm{H}_{2} \mathrm{O} \\
\text { equivalence }\end{array}$ & Reaction time, h & Major species present & Other species present & Yield, \% \\
\hline $\mathrm{Et}_{3} \mathrm{SiH}$ & 5.0 & 0.5 & 70 & $3 a$ & - & 71 \\
\hline \multirow[t]{8}{*}{$1 a$} & 1.0 & 0.5 & 70 & $3 a$ & - & 73 \\
\hline & 1.0 & 0.5 & 24 & $3 a$ & - & 72 \\
\hline & 1.0 & 0.5 & 1 & $3 a$ & - & 69 \\
\hline & 0.1 & 0.5 & 1 & $1 a$ & $3 a, 2 a$ & * \\
\hline & 0.1 & 0.5 & 3 & $1 a$ & $3 a, 2 a$ & * \\
\hline & 0.1 & 0.5 & 24 & $1 a, 3 a$ & $2 a$ & * \\
\hline & 0.1 & 0.5 & 48 & $3 a$ & $2 a$ & * \\
\hline & 0.0 & 1.0 & 24 & No reaction & & \\
\hline $\mathrm{PhMe}_{2} \mathrm{H}$ & 5.0 & 0.5 & 70 & $3 b$ & - & 78 \\
\hline \multirow[t]{9}{*}{$1 b$} & 1.0 & 0.2 & 1 & $3 b$ & $1 b, 2 b$ & * \\
\hline & 1.0 & 0.2 & 3 & $3 b$ & $1 b, 2 b$ & * \\
\hline & 1.0 & 0.2 & 72 & $3 b$ & $1 b, 2 b$ & * \\
\hline & 1.0 & Excess & 1 & $3 b$ & - & * \\
\hline & 1.0 & Excess & 24 & $3 b$ & - & * \\
\hline & 0.5 & 0.5 & 1 & $3 b$ & - & * \\
\hline & 0.5 & 0.5 & 3 & $3 b$ & - & 76 \\
\hline & 0.1 & 0.5 & 1 & $3 b$ & - & * \\
\hline & 0.1 & 0.5 & 3 & $3 b$ & - & 77 \\
\hline $\mathrm{Ph}_{3} \mathrm{SiH}$ & 5.0 & 0.0 & 70 & $3 c$ & $3 b$ & * \\
\hline $1 c$ & 5.0 & 0.5 & 70 & $3 c$ & - & 75 \\
\hline
\end{tabular}

*\% yield of $\mathbf{3 a - 3}$ was not determined as it was a mixture.

$=0.01 \mathrm{ppm}$ ) was already evident after only $1 \mathrm{~h}$ reaction time. Even when the catalyst concentration was further increased to 0.5 and $5.0 \mathrm{~mol} \%$, the reaction proceeded in the same manner as when using a lower amount of catalyst (Supplementary Figures 17, 18). Decreasing the amount of $\mathrm{H}_{2} \mathrm{O}$ to $0.2 \mathrm{eq}$ at $1.0 \mathrm{~mol} \%\left(\mathrm{C}_{6} \mathrm{~F}_{5}\right)_{3} \mathrm{~B}\left(\mathrm{OH}_{2}\right)$ left some of the starting material, $\mathbf{1 b}$, and presence of the silanol, $\mathrm{PhMe}_{2} \mathrm{SiOH}$ (2b), was also observed (Supplementary Figures 20, 21). It can be inferred that the addition of $\mathrm{H}_{2} \mathrm{O}$ plays an important role in the reaction, especially, in terms of the length of time needed to complete the reaction. Conversely, using an excess amount of $\mathrm{H}_{2} \mathrm{O}$ hastened the reaction while using the same catalyst concentration of $1.0 \mathrm{~mol} \%\left(\mathrm{C}_{6} \mathrm{~F}_{5}\right)_{3} \mathrm{~B}\left(\mathrm{OH}_{2}\right)$. The reaction was observed to have been completed after $1 \mathrm{~h}$ (Supplementary Figure 22).

To further investigate the effect of reaction time and the necessity of $\mathrm{H}_{2} \mathrm{O}$, the direct synthesis of $\mathrm{Ph}_{3} \mathrm{SiOSiPh}_{3}, 3 \mathrm{c}$, was conducted at $5.0 \mathrm{~mol} \%\left(\mathrm{C}_{6} \mathrm{~F}_{5}\right)_{3} \mathrm{~B}\left(\mathrm{OH}_{2}\right)$, for $70 \mathrm{~h}$ with and without 
TABLE 2 | Scope of substrates and products in the synthesis of oligosiloxanes, cyclo $\mathbf{3 d}$, 3f, 4f, and linear $\mathbf{3 d - 3 e , ~ 4 e , ~ 5 e . ~}$

\begin{tabular}{|c|c|c|c|c|c|}
\hline Substrate & Catalyst, mol\% & $\begin{array}{c}\mathrm{H}_{2} \mathrm{O} \\
\text { equivalence }\end{array}$ & Reaction time, $\mathrm{h}$ & Major species present & Other (or minor) species present \\
\hline $\mathrm{Et}_{2} \mathrm{SiH}_{2}$ & 2.0 & 1.0 & 1 & $3 d$ & cyclo 3d \\
\hline & 2.0 & 1.0 & 24 & $3 d$ & cyclo 3d \\
\hline & 2.0 & 1.0 & 48 & cyclo 3d & $3 d$ \\
\hline $\mathrm{PhMeSiH}_{2}$ & 2.0 & 1.0 & 1 & $3 e$ & - \\
\hline \multirow[t]{4}{*}{$1 e$} & 2.0 & 1.0 & 6 & $3 e$ & - \\
\hline & 2.0 & 1.0 & 24 & $3 e, 4 e$ & $5 e$ \\
\hline & 2.0 & 1.0 & 48 & $3 e, 4 e$ & $5 e$ \\
\hline & 2.0 & 0.0 & 96 & $3 e$ & - \\
\hline
\end{tabular}

the addition of $\mathrm{H}_{2} \mathrm{O}$. It was observed that for reactions left for a longer period of time, the addition of $\mathrm{H}_{2} \mathrm{O}$ seemed to be not necessary, and the presence of the catalyst $\left(\mathrm{C}_{6} \mathrm{~F}_{5}\right)_{3} \mathrm{~B}\left(\mathrm{OH}_{2}\right)$, alone is sufficient enough to yield the desired product. As previously observed with the other silanes, a mixture of $\mathrm{Ph}_{3} \mathrm{SiH}$ (1c) with $\mathrm{H}_{2} \mathrm{O}$ in the absence of the catalyst did not show any sign of a reaction (Supplementary Figures 27, 28).

Using the same protocol as for the tertiary silanes (1a-c), the reaction of secondary hydrosilanes (1d-f) was performed and generally resulted to the direct synthesis of oligomeric siloxanes with 3-5 repeat units identified based on ESI-MS. Three different secondary silanes were used: $\mathrm{Et}_{2} \mathrm{SiH}_{2}, \mathbf{1 d}, \mathrm{PhMeSiH}_{2}, \mathbf{1 e}$, and $\mathrm{Ph}_{2} \mathrm{SiH}_{2}$, 1f. Depending on the substrate used, the products were observed to be linear and/or cyclic siloxane chains (Scheme 2; Supplementary Figures 29-31). Furthermore, in the case of 1e there was evidence of siloxanediol formation (Diemoz et al., 2016) indicating its role as an intermediate in the synthesis of the higher siloxanes under these conditions.

Similar to the synthesis of symmetrical disiloxanes, the reaction proceeded at a faster rate in the presence of $\mathrm{H}_{2} \mathrm{O}$. The reaction with 1e gave mostly linear oligomers containing 3-5 repeat units, with a minor amount of oligosiloxanes containing 67 repeat units. The oligomerization of dialkylsilane, $\mathbf{1 d}$, resulted to both linear and cyclic products with $3 \mathrm{Si}-\mathrm{O}$ units, while the diarylsilane, 1f, resulted to cyclic oligosiloxanes with $n=3$ and 4 . For 1d, it is interesting to note that after $48 \mathrm{~h}$ it forms a cyclic species but if left for longer reverts back to the linear species (Table 2).

\section{Intramolecular Synthesis of Tethered Siloxanes Using a $\left(\mathrm{C}_{6} \mathrm{~F}_{5}\right)_{3} \mathrm{~B}\left(\mathrm{OH}_{2}\right)$ Catalyst}

We previously reported a preliminary study on the preparation of symmetrical naphthalene bridged disilanes with a Si-OSi motif (Rabanzo-Castillo et al., 2019). Having success in forming linear siloxanes from tertiary and secondary silanes, it intrigued us to perform intramolecular reactions with catalytic amounts of $\left(\mathrm{C}_{6} \mathrm{~F}_{5}\right)_{3} \mathrm{~B}\left(\mathrm{OH}_{2}\right)$ to produce tethered and unsymmetrical siloxanes. In order to perform such reactions, disilyl precursors $(\mathbf{7 a - c})$ that resemble tertiary silanes having $\mathrm{Si}-\mathrm{H}$ bonds were prepared using Grignard reactions from dibrominated bridge precursors (6a-b; Scheme 3). The synthesized disilyl tertiary silane precursors were obtained in high yields (Supplementary Figures 32-44) and were later subjected to intramolecular reactions with the catalyst under aerobic conditions to obtain the desired tethered siloxanes (Supplementary Figures 45-57), cyclic structures with 6-7 membered rings (8a-c; Scheme 3).

The intramolecular dehydrocoupling step was optimized for each of the disilyl tertiary silane precursors. $7 \mathbf{a}\left(\delta_{\mathrm{Si}}=-13.7\right.$, $-22.5 \mathrm{ppm}$ ) is a solid therefore was dissolved in toluene prior to the intramolecular dehydrocoupling using $5.0 \mathrm{~mol} \%$ $\left(\mathrm{C}_{6} \mathrm{~F}_{5}\right)_{3} \mathrm{~B}\left(\mathrm{OH}_{2}\right)$ at $90^{\circ} \mathrm{C}$ for $24 \mathrm{~h}$. Under these conditions, the only product observed was $\mathbf{8 a}\left(\delta_{\mathrm{Si}}=-9.9,-14.1 \mathrm{ppm}\right)$. The disilyl tertiary silane precursors $7 \mathbf{b}\left(\delta_{\mathrm{Si}}=-11.0,-21.6 \mathrm{ppm}\right)$ and $7 \mathrm{c}\left(\delta_{\mathrm{Si}}=-13.3\right)$ are liquids and therefore were able to undergo intramolecular dehydrocoupling reactions without the addition of solvents, but the catalysis was more efficient with the addition of toluene along with $1.0 \mathrm{~mol} \%\left(\mathrm{C}_{6} \mathrm{~F}_{5}\right)_{3} \mathrm{~B}\left(\mathrm{OH}_{2}\right)$ at $22^{\circ} \mathrm{C}$ for $3 \mathrm{~h}$, yielding $\mathbf{8 b}\left(\delta_{\mathrm{Si}}=10.9,3.7 \mathrm{ppm}\right)$ and $\mathbf{8 c}\left(\delta_{\mathrm{Si}}\right.$ $=7.2$ ), respectively. The crude siloxanes $(\mathbf{8 a}-\mathbf{c})$ were filtered through a Florisil pad to remove the catalyst. Although cyclic siloxanes are known to degrade when subjected to purification by silica gel column chromatography, compounds $\mathbf{8 a - 8 c}$ could be purified by column chromatography, using hexanes as an eluent (Blackwell et al., 1999). The ${ }^{29} \mathrm{Si}\left\{{ }^{1} \mathrm{H}\right\}$ NMR chemical shifts of the purified product matched that of the filtered product suggesting that, in this case, the products do not degrade on silica gel (Supplementary Figures 45-57).

Single crystals were grown for compounds $7 \mathbf{a}$ and $\mathbf{8 a}$ by slow evaporation of pentane and ethyl acetate, respectively; the crystal structures were solved by single crystal X-ray diffraction (Figure 1; Supplementary Table 1). From the molecular structure of product $7 \mathbf{a}$ it is evident that due to the steric bulk from the phenyl groups on the silyl substituents and the flexibility at $\mathrm{C} 19$, the $\mathrm{Si}-\mathrm{H}$ bonds are quite far from each other. The two silicon atoms are $4.292 \AA$ apart. The molecular structure 


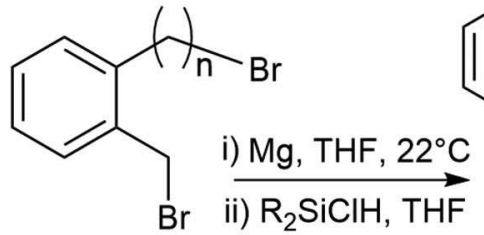

6a-b
a: $n=0$

b: $n=1$<smiles>[R][SiH]([R])Cc1ccccc1C(C)(C)C</smiles>

7a-c

a: $\mathrm{n}=0 ; \mathrm{R}=\mathrm{Ph}$

b: $n=0 ; R=M e$

c: $n=1 ; R=M e$
$\mathrm{R}$

$\mathrm{S}$
$\mathrm{Si}$
$\mathrm{I}$
$\mathrm{H}$

$1.0 \mathrm{~mol} \%$

$\underset{22^{\circ} \mathrm{C}}{\stackrel{\left(\mathrm{C}_{6} \mathrm{~F}_{5}\right)_{3} \mathrm{~B}\left(\mathrm{OH}_{2}\right)}{\longrightarrow}}$

$-\mathrm{H}_{2}$

SCHEME 3 | Intramolecular synthesis of symmetric and asymmetric tethered siloxanes using a $\left(\mathrm{C}_{6} \mathrm{~F}_{5}\right)_{3} \mathrm{~B}\left(\mathrm{OH}_{2}\right)$ catalyst.
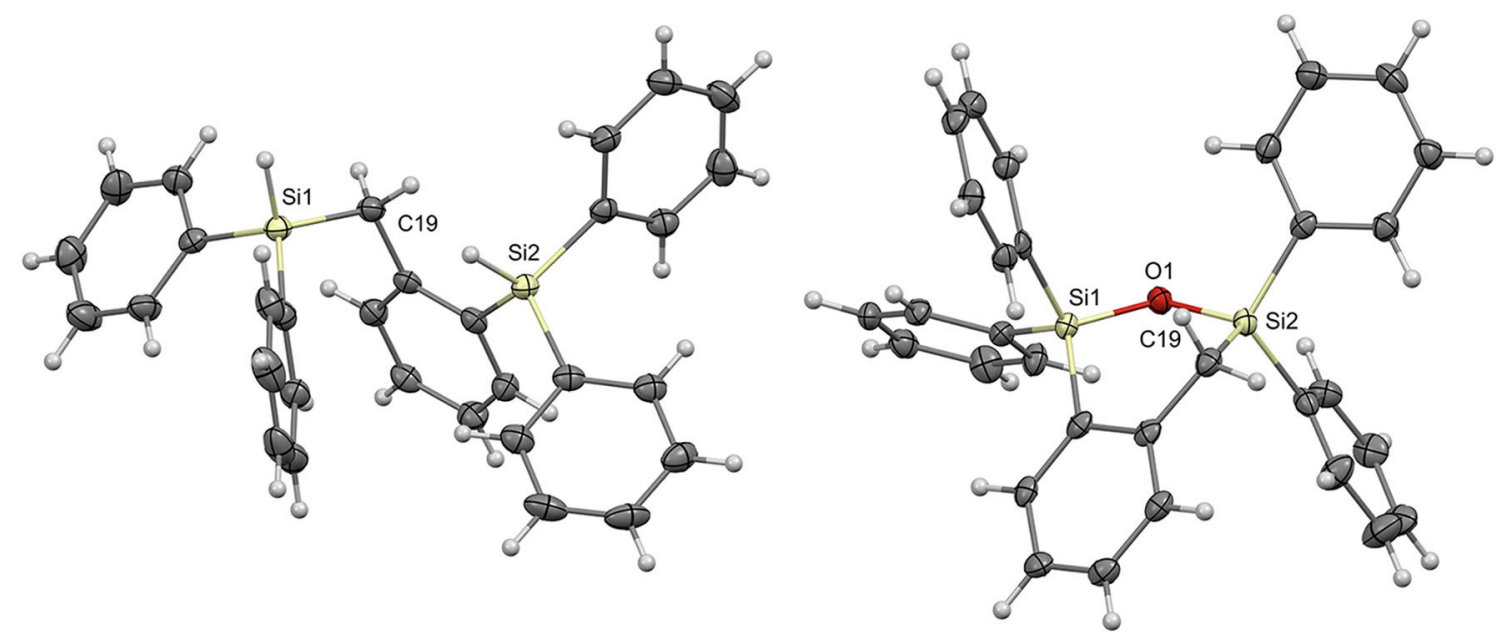

FIGURE 1 | Molecular structures of 7a (Left) and $\mathbf{8 a}$ (Right) with thermal ellipsoids drawn at the 50\% probability level.

of $\mathbf{8 a}$ shows that the newly formed 6-membered cyclic structure, containing the Si1-O1-Si2 bond, results in a slightly distorted boat shaped geometry with Sil and C19 as the central two atoms. The distortion can be attributed to the presence of the $\mathrm{Si}-\mathrm{O}-\mathrm{Si}$ linkage and phenyl substituents lengthening the bonds through these atoms in addition to the wider Si-O-Si bond angle of $124.41^{\circ}$.

\section{Mechanistic Considerations}

Looking at the simplest system, using the tertiary silanes (1a-c), the mechanism of the catalysis was investigated. The reaction process involves the formation of the silanol intermediate and generation of either hydrogen gas or $\mathrm{H}_{2} \mathrm{O}$ to give the disiloxanes, 3a-c, depending on which pathway is operating (route I or route II; Scheme 4). It is important to note that the two pathways are experimentally distinct. Creation of $\mathbf{2}$ from $\mathbf{1}$ involves the loss of $\mathrm{H}_{2}$. Similarly, with a $50 \%$ conversion to 2 , the silanol (2) can react with the hydrosilane (1) to form the disiloxane (3) with concomitant loss of $\mathrm{H}_{2}$ in a dehydrocoupling reaction (route I; Scheme 4). However, if all of 1 becomes 2 (more likely under higher concentrations of $\mathrm{H}_{2} \mathrm{O}$ ), then the subsequent condensation of the silanols eliminates $\mathrm{H}_{2} \mathrm{O}$ in a condensation reaction to form a disiloxane (route II; Scheme 4).

Kinetic studies were attempted to better probe the postulated mechanism, however, were not possible due to the difficulty in matching the experimental conditions by NMR spectroscopy. Moreover, each individual reactant $(\mathbf{1} \mathbf{a}-\mathbf{c})$ gave reactions that were too fast with $\left(\mathrm{C}_{6} \mathrm{~F}_{5}\right)_{3} \mathrm{~B}\left(\mathrm{OH}_{2}\right)$. To elaborate the routes occurring, neat reactions of individual silanols (2a, 2b), under the same reaction conditions of the hydrosilanes, were also performed. Hydrosilanes $\left(\mathbf{1}, \mathrm{R}_{3} \mathrm{SiH}\right)$ are said to be more susceptible to Brønsted acid-catalyzed reactions (Muzafarov, 2011) which is generally what was observed (Table 3). Interestingly, the addition of 0.5 eq. of $\mathrm{H}_{2} \mathrm{O}$ increased the rate of reaction of $\mathbf{1 a}$ to $\mathbf{3 a}$, from $50 \%$ conversion to $>99 \%$ after $1 \mathrm{~h}$, while the same addition of $\mathrm{H}_{2} \mathrm{O}$ did not have an impact on the already rapid conversion of $\mathbf{1 b}$ to $\mathbf{3 b}$. For the case of a catalytic reaction starting with $\mathrm{Et}_{3} \mathrm{SiOH}, 2 \mathrm{a}$, the reaction took longer than the reaction starting with $1 \mathrm{a}$ to reach completion (24 and $3 \mathrm{~h}$, respectively). However, the same reaction starting 


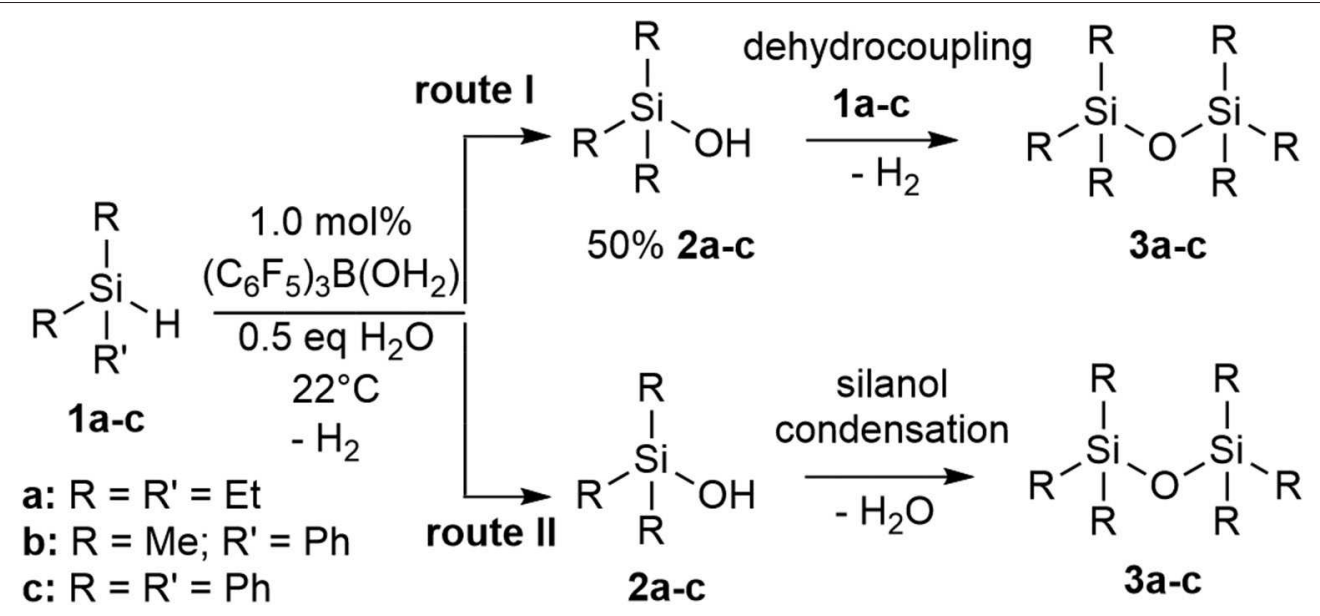

SCHEME 4 | Two potential routes to disiloxane from silane via silanol.

TABLE 3 | Comparative reactivities of $\mathrm{SiH}$ and $\mathrm{SiOH}$ groups in the presence of catalytic $\left(\mathrm{C}_{6} \mathrm{~F}_{5}\right)_{3} \mathrm{~B}\left(\mathrm{OH}_{2}\right)$.

\begin{tabular}{|c|c|c|}
\hline$\left(\mathrm{C}_{6} \mathrm{~F}_{5}\right)_{3} \mathrm{~B}\left(\mathrm{OH}_{2}\right)+$ & Reaction time, h & Conversion, \% \\
\hline $1 \mathbf{a}$ (in air) & $1 \mathrm{~h}$ & 50 \\
\hline $1 \mathbf{a}$ (in air) & $3 h$ & $>99$ \\
\hline $\mathbf{1 b}$ (in air) & $1 \mathrm{~h}$ & $>99$ \\
\hline $\begin{array}{l}\mathbf{1 a} \text { (in air) } \\
+0.5 \text { eq } \mathrm{H}_{2} \mathrm{O}\end{array}$ & $1 \mathrm{~h}$ & $>99$ \\
\hline $\begin{array}{l}\mathbf{1 b} \text { (in air) } \\
+0.5 \text { eq } \mathrm{H}_{2} \mathrm{O}\end{array}$ & $1 \mathrm{~h}$ & $>99$ \\
\hline $\mathbf{2 a}$ (in air) & $1 \mathrm{~h}$ & No reaction \\
\hline $\mathbf{2 a}$ (in air) & $24 \mathrm{~h}$ & $>99$ \\
\hline $\mathbf{2 a}$ (limited air) & $24 \mathrm{~h}$ & No reaction \\
\hline $\mathbf{2 b}$ (in air) & $1 \mathrm{~h}$ & $>99$ \\
\hline $\mathbf{2 b}$ (limited air) & $24 \mathrm{~h}$ & $>99$ \\
\hline $\mathbf{1 b}+\mathbf{2 b}$ (in air) & Immediate & $>99$ \\
\hline $\mathbf{1 b}+\mathbf{2 a}$ (in air) & $1 \mathrm{~h}$ & $>99$ \\
\hline
\end{tabular}

with $\mathrm{PhMe}_{2} \mathrm{SiOH}, \mathbf{2 b}$, proceeded to completion within an hour. Limiting air in the reactions starting with the silanol (e.g., 2a and $\mathbf{2 b}$ ) only made a significant difference in the reaction rate for $\mathbf{2 a} \mathbf{2} \mathbf{2} \mathbf{b}$ was unaffected. When a 1:1 mixture of $\mathrm{PhMe}_{2} \mathrm{SiH}, \mathbf{1 b}$, and $\mathrm{PhMe}_{2} \mathrm{SiOH}, \mathbf{2 b}$, were reacted, a rapid exotherm and buildup of pressure was observed resulting to almost full conversion after only a few seconds (Table 3 ). These results suggest, not only that the reaction with $\mathbf{1} \mathbf{b}$ is the most rapid in the series, but also, that both routes to form the disiloxane are possible under the catalytic conditions.

To elaborate on the relative rates of reaction for substrates 1a-c, and to have a better indication of chemoselectivity, a crosscondensation reaction of a 1:1:1 mixture of $\mathrm{Ph}_{3} \mathrm{SiH}(1 \mathrm{c}), \mathrm{Et}_{3} \mathrm{SiH}$ (1a), and $\mathrm{H}_{2} \mathrm{O}$ was performed with $1 \mathrm{~mol} \%$ catalyst loading. The reaction resulted in the rapid evolution of $\mathrm{H}_{2}$ and was observed to reach completion soon after the addition of $\mathrm{H}_{2} \mathrm{O}$ into the reaction mixture (Supplementary Figures 58-61). As expected, the reaction resulted to three different products-two homocoupling products, $\mathrm{Ph}_{3} \mathrm{SiOSiPh}_{3}(\mathbf{3 c})$ and $\mathrm{Et}_{3} \mathrm{SiOSiEt}_{3}$ (3a) and a cross-coupling product, $\mathrm{Ph}_{3} \mathrm{SiOSiEt}_{3}$. A crude estimate using the ${ }^{1} \mathrm{H}$ NMR spectrum of the product mixture revealed a ratio of 2.5 3c: $1 \mathrm{Ph}_{3} \mathrm{SiOSiEt}_{3}$ : 2 3a, instead of a 1:1:1 ratio which would be expected if the $\mathbf{1 a}$ and $\mathbf{1 c}$ reacted at the same rate. This deviation can be explained by the difference in kinetics and solubilities of the two reactants. $1 \mathrm{c}$ alone and $1 \mathrm{a}$ alone require 2 and $3 \mathrm{~h}$ reaction time, respectively, to reach full conversion, while $\mathbf{1 b}$ is even more rapid at $1 \mathrm{~h}$. To further confirm this claim, cross-condensation reaction between $\mathbf{1 b}$ and $\mathbf{1 a}$ (Supplementary Figure 62) resulted to $\mathbf{3 b}$ and $\mathrm{PhMe}_{2} \mathrm{SiOSiEt}_{3}$ as the major products in a 1:6 ratio and, no $\mathbf{3 a}$ was observed. Therefore, the reactivity to form disiloxanes $(\mathbf{3 a}-\mathbf{c})$ from the three tertiary silane substrates under the catalytic conditions follows the trend $\mathbf{1 b}>$ 1c $>$ la.

Cross-coupling between $\mathrm{PhMe}_{2} \mathrm{SiH}, \mathbf{1 b}$, and $\mathrm{Et}_{3} \mathrm{SiOH}$, 2a, on the other hand, resulted to a 1:1:1 ratio of $\mathbf{3 b}$ to the cross product, $\mathrm{PhMe}_{2} \mathrm{SiOSiEt}_{3}$ to $3 \mathrm{a}$. In this case, both homo-coupling products were obtained along with the expected unsymmetrical crosscoupling product (Supplementary Figures 63, 64) and the ratio suggests that the difference in the aforementioned reactivity trend is mostly likely due to the rate determining formation of the silanol (2) from the silane (1), which is most sluggish for the conversion of 1a to $2 \mathbf{a}$.

Monitoring the catalytic intermediates and the formation of silanol experimentally in situ in order to capture the impact of ppm-level changes of the substrates was challenging. Nevertheless, NMR tube reactions wherein $2.6 \mathrm{mmol}$ each of $\mathbf{1 b}$ and $\mathbf{2} \mathbf{b}$ were reacted, separately, with $0.1 \mathrm{~mol} \%$ of $\left(\mathrm{C}_{6} \mathrm{~F}_{5}\right)_{3} \mathrm{~B}\left(\mathrm{OH}_{2}\right)$. Experimentally, partial conversion to $\mathbf{2} \mathbf{b}$ and $\mathbf{3 b}$ after $4 \mathrm{~h}$ was observed with $\mathbf{1 b}$, which is significantly slower compared to the reaction performed with constant stirring. It is interesting to note that when using a hydrosilane (e.g., $\mathbf{1 b}$ ) as the starting material, the products that have been formed (i.e., $\mathbf{2 b}$ and $3 \mathbf{b})$ after $4 \mathrm{~h}$ tend to revert back to $\mathrm{PhMe}_{2} \mathrm{SiH}$ after letting the reaction stand for a total of $96 \mathrm{~h}$ (Supplementary Figure 65). This indicates that the reaction is not quite as simple as 
implied, with reversibility at play along with the direct siloxane formation. In contrast, using the silanol (2b) as the starting material, full conversion was observed after $24 \mathrm{~h}$ and the product (3b) did not convert back to the silanol substrate after $96 \mathrm{~h}$ (Supplementary Figure 66).

In summary, the results obtained from cross-coupling and control reactions indicate that the prevalent mechanism is where the hydrosilane $\left(\mathrm{R}_{3} \mathrm{SiH}\right)$ and silanol $\left(\mathrm{R}_{3} \mathrm{SiOH}\right)$ undergo dehydrocoupling to yield the disiloxane product (3), but under high concentration regimes of some silanol substrates (e.g., as confirmed for $\mathbf{2} \mathbf{b}$ ) the silanol condensation route is possible. The postulated reaction mechanism, therefore, for the transformation is a modified Pier-Rubinsztajn reaction (Scheme 5). The process involves: i) the hydrolysis of $\mathrm{Si}-\mathrm{H}$ to $\mathrm{Si}-\mathrm{OH}$ using $\left(\mathrm{C}_{6} \mathrm{~F}_{5}\right)_{3} \mathrm{~B}\left(\mathrm{OH}_{2}\right)$ with subsequent release of $\mathrm{H}_{2}$ gas, followed by ii) nucleophilic attack of silanol $\left(2, \mathrm{R}_{3} \mathrm{SiOH}\right)$ to the hydrosilane $\left(\mathbf{1}, \mathrm{R}_{3} \mathrm{SiH}\right)$ to form a disiloxane and another equivalent of $\mathrm{H}_{2}$ gas (Scheme 5).

In addition to the conversion of the three components (1, 2, 3) over time, the catalyst can have different interactions with the substrates $(\mathbf{1}, \mathbf{2})$ and $\mathrm{H}_{2} \mathrm{O}$ that are present during the reaction. Decomposition of $\left(\mathrm{C}_{6} \mathrm{~F}_{5}\right)_{3} \mathrm{~B}\left(\mathrm{OH}_{2}\right)$ catalyst via $\mathrm{B}-\mathrm{C}$ bond protonolysis is highly probable in strongly basic conditions and high temperatures (Bradley et al., 1996; Ashley et al., 2009; Scott et al., 2015). Generally, Frustrated Lewis Pairs (FLP's) demonstrate high sensitivity to moisture. The high Lewis acidity of $\mathrm{B}\left(\mathrm{C}_{6} \mathrm{~F}_{5}\right)_{3}$ leads to strong complexation with $\mathrm{H}_{2} \mathrm{O}$ and deprotonation even with moderately strong bases can occur irreversibly (Bergquist et al., 2000). However, the method described in this article demonstrated moisture tolerance of the $\left(\mathrm{C}_{6} \mathrm{~F}_{5}\right)_{3} \mathrm{~B}\left(\mathrm{OH}_{2}\right)$ catalyst as it was conducted at room temperature, and due to the lack of any strong base in a reaction with a hydrosilane as the sole substrate.

Another way to view the direct synthesis of disiloxanes is through a non-conventional mechanism which features multiple catalytically relevant species and series of competitive reactions (Scheme 6). The formation of disiloxanes can be regarded as a Lewis acid-catalyzed reaction, a water-mediated or a silanol-mediated type of catalysis ( $Y u$ et al., 2018). In the Lewis acid catalysis (Scheme 6), the $\mathrm{Si}-\mathrm{H}$ bond of the silane is activated by $\mathrm{B}\left(\mathrm{C}_{6} \mathrm{~F}_{5}\right)_{3}$ and then will further react with a silanol to produce the disiloxane with concomitant release of $\mathrm{H}_{2}$. By contrast, hydrosilylation reactions catalyzed by $B\left(\mathrm{C}_{6} \mathrm{~F}_{5}\right)_{3}$ are generally characterized by the formation of borane-silane complex (Parks and Piers, 1996; Parks et al., 2000; Rendler and Oestreich, 2008; Sakata and Fujimoto, 2013; Zhang et al., 2016; Cheng et al., 2018). Furthermore, several experimental and theoretical mechanistic studies have suggested that boranecatalyzed reactions of siloxanes are initiated by activation of the silane Si-H bond (Parks et al., 2000; Hog and Oestreich, 2009; Mewald and Oestreich, 2012; Sakata and Fujimoto, 2013; Mathew et al., 2017).

Since the $\mathrm{B}\left(\mathrm{C}_{6} \mathrm{~F}_{5}\right)_{3}$ catalyst has strong affinity with $\mathrm{H}_{2} \mathrm{O}$, the Lewis-acid mediated pathway (Scheme 6) is not enough on its own to describe the formation of the disiloxane. The reaction could also possibly proceed via a water-mediated catalytic cycle (Scheme 6). For this reaction pathway, $\mathrm{R}_{3} \mathrm{SiH}$ is initially activated by the $\left(\mathrm{C}_{6} \mathrm{~F}_{5}\right)_{3} \mathrm{~B}\left(\mathrm{OH}_{2}\right)$ catalyst, which is in equilibrium with
$\mathrm{B}\left(\mathrm{C}_{6} \mathrm{~F}_{5}\right)_{3}$ in the presence of $\mathrm{H}_{2} \mathrm{O}$. While $\mathrm{B}\left(\mathrm{C}_{6} \mathrm{~F}_{5}\right)_{3}$ is a potent Lewis acid $\left(\mathrm{C}_{6} \mathrm{~F}_{5}\right)_{3} \mathrm{~B}\left(\mathrm{OH}_{2}\right)$, can be regarded as a strong Brønsted acid (Bergquist et al., 2000). The Si-H activation step can lead to Lewis acidic silicon atom, which for this case then interacts with oxygen lone pair of the pre-formed silanol to generate $\mathbf{3}$ and eliminate $\mathrm{H}_{2}$. One final catalytic possibility, under higher concentrations of silanol (2) is that it can mediate the catalysis. Here the silanol (2) interacts with $\left(\mathrm{C}_{6} \mathrm{~F}_{5}\right)_{3} \mathrm{~B}\left(\mathrm{OH}_{2}\right)$ catalyst via the oxygen atom which activates it toward a reaction with silane (1) to produce 3 and $\mathrm{H}_{2}$ while regenerating the catalyst/silanol adduct (Scheme 6).

The observations from the control and competition reactions suggest that the water-mediated catalysis (Scheme 6) is the most probable catalytic pathway which will lead to the formation of disiloxane. Nonetheless, there also might be a competition between more than one catalytic cycle happening simultaneously or under different concentration regimes of substrates 1 (e.g., toward the start of the reaction) and 2 (e.g., toward full conversion to 3 ). Therefore, this seemingly simple reaction may have an incredibly complex mechanism.

\section{Catalyst Recycling Studies}

Catalyst recycling, that is the reuse of the $\left(\mathrm{C}_{6} \mathrm{~F}_{5}\right)_{3} \mathrm{~B}\left(\mathrm{OH}_{2}\right)$ catalyst, was considered to demonstrate the efficiency and sustainability of the direct synthetic route to oligosiloxanes. For this purpose, all experiments were conducted with constant stirring to allow efficient removal of hydrogen gas and favor the formation of disiloxane product. The reactions were monitored by ${ }^{1} \mathrm{H}$ NMR spectroscopy to estimate the reaction time needed for each substrate to reach completion. From these studies, 3, 1 and $2 \mathrm{~h}$ reaction time was applied for $\mathrm{Et}_{3} \mathrm{SiH}$ (1a), $\mathrm{PhMe}_{2} \mathrm{SiH}(\mathbf{1 b})$ and $\mathrm{Ph}_{3} \mathrm{SiH}$ (1c), respectively.

For $\mathrm{Et}_{3} \mathrm{SiOSiEt}_{3}, \mathbf{3} \mathbf{a}$, the catalyst was recovered conveniently as it settled at the bottom of the flask after the stirring was stopped. The product was isolated by addition of $n$-pentane followed by decantation using a cannula. Looking at catalyst loading (0.1$5.0 \mathrm{~mol} \%$ ) there was very little discrepancy in isolated yield over this range and the best TOF achieved was $167 \mathrm{~h}^{-1}$ with $0.1 \mathrm{~mol} \%$ catalyst loading (Figure 2; Supplementary Figure 67; Supplementary Table 2). The dependence on catalyst loading for the reaction of $\mathbf{1 b}$ to form $\mathrm{PhMe}_{2} \mathrm{SiOSiMe}_{2} \mathrm{Ph}, \mathbf{3} \mathbf{b}$, is far less pronounced with the given experimental conditions allowing for an increase in TOF with a decrease in catalyst loading; $900 \mathrm{~h}^{-1}$ TOF was achieved at $0.1 \mathrm{~mol} \%$ loading (3b, Figure 2; Supplementary Figure 68; Supplementary Table 3). The reaction was completed after $1 \mathrm{~h}$ as observed by ${ }^{1} \mathrm{H}$ NMR spectroscopy. In this case, the $\left(\mathrm{C}_{6} \mathrm{~F}_{5}\right)_{3} \mathrm{~B}\left(\mathrm{OH}_{2}\right)$ remained soluble even after the formation of $\mathbf{3 b}$. Therefore, due to the challenges of directly testing the catalyst recyclability on such a small scale (e.g., $0.1 \mathrm{~mol} \%$ loading), the activity of the catalyst (at $1.0 \mathrm{~mol} \%$ loading) was demonstrated by adding a constant amount of $\mathbf{1 b}$ to the same flask every hour after testing the degree of completion by ${ }^{1} \mathrm{H}$ and ${ }^{29} \mathrm{Si}$ NMR spectroscopy. After 5 cycles, $\mathbf{3} \mathbf{b}$ was isolated and the $\%$ yield for each trial was reported as the average of 5 cycles (94\%). Similarly, using $1 \mathrm{c}$ as the substrate, the reaction rate exhibited independence of catalyst loading with a TOF of $485 \mathrm{~h}^{-1}$ at $0.1 \mathrm{~mol} \%$ loading (3c, Figure 2; Supplementary Figure 69; 


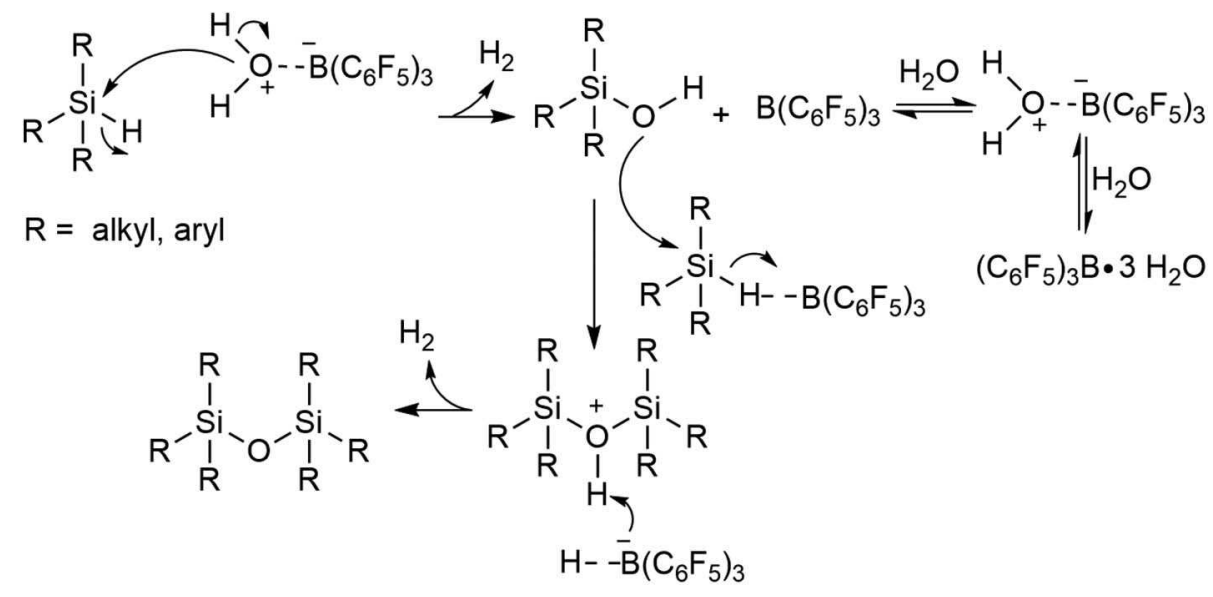

SCHEME 5 | Proposed mechanism for the catalytic formation of disiloxanes using $\left(\mathrm{C}_{6} \mathrm{~F}_{5}\right)_{3} \mathrm{~B}\left(\mathrm{OH}_{2}\right)$.

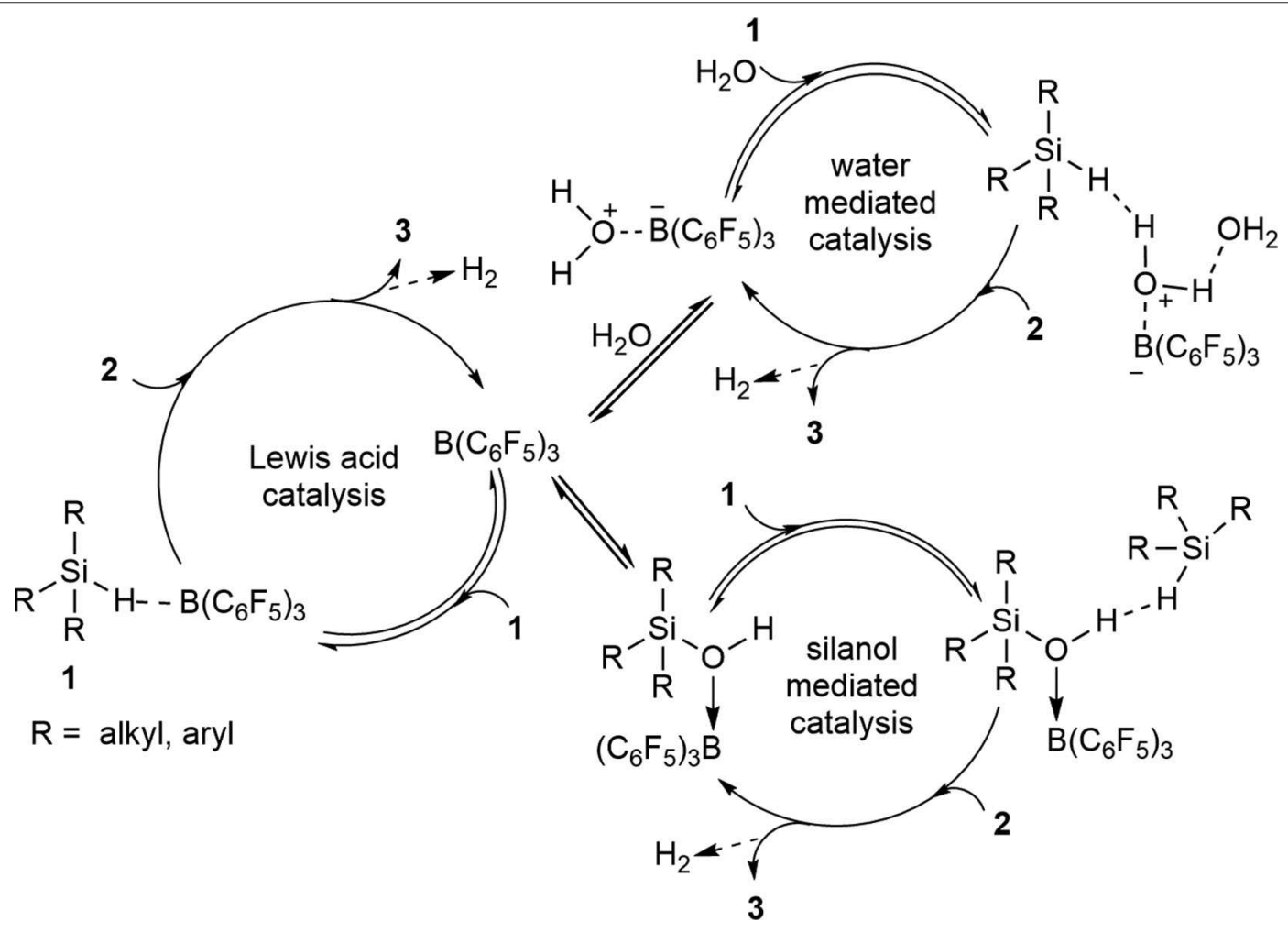

SCHEME 6 | A catalytic mechanism with multiple competing catalytic pathways to form disiloxanes.

Supplementary Table 4). However, the reaction required the addition of toluene to dissolve the two solids (1c and catalyst). Similar to the reaction with $\mathbf{1} \mathbf{b}$, given that the reaction was performed in a mmol scale, a constant volume of $3.0 \mathrm{M}$ solution of $1 \mathrm{c}$ in toluene was added sequentially to the same flask at 1.0 mol\% catalyst loading. The product $\mathrm{Ph}_{3} \mathrm{SiOSiPh}_{3}, 3 \mathrm{c}$, was again isolated collectively at the end of the fifth cycle (98\%).

To demonstrate the recycling by separating the catalyst and product after each cycle, both $0.5 \mathrm{~mol} \%$ and $1.0 \mathrm{~mol} \%$ catalyst loadings of $\left(\mathrm{C}_{6} \mathrm{~F}_{5}\right)_{3} \mathrm{~B}\left(\mathrm{OH}_{2}\right)$ were chosen. The results showed that the activity of the catalyst for each cycle is almost the same (within experimental error) for up to five repeats (Figure 3). The volatility and solubility of the substrate plays an important role in facilitating the formation of the disiloxane product in excellent yields. Since the reactions were performed with constant stirring, it can be assumed that some of the $\mathrm{Et}_{3} \mathrm{SiH}$ may have been lost prior to its conversion to product (see lower yield for 3a, Figure 2). In addition, the solubility of the catalyst was 


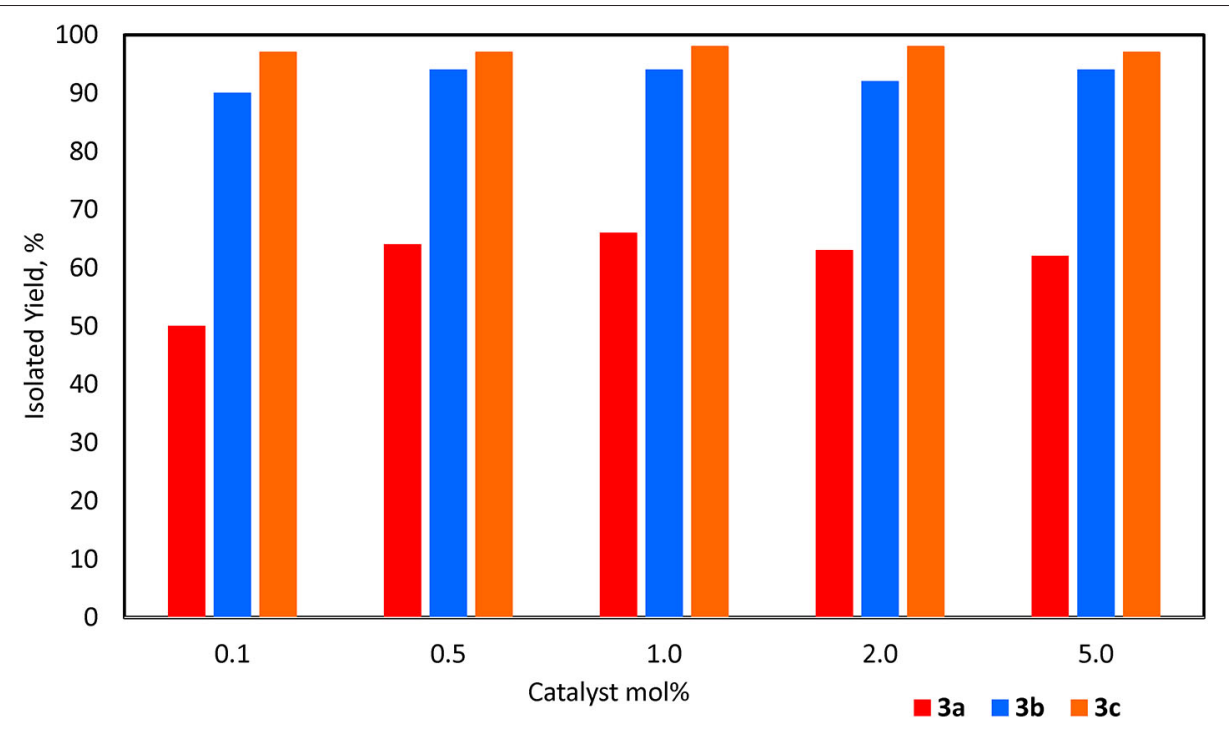

FIGURE 2 | Yields for 3a-c with catalyst loadings 0.1-5.0 mol\%.

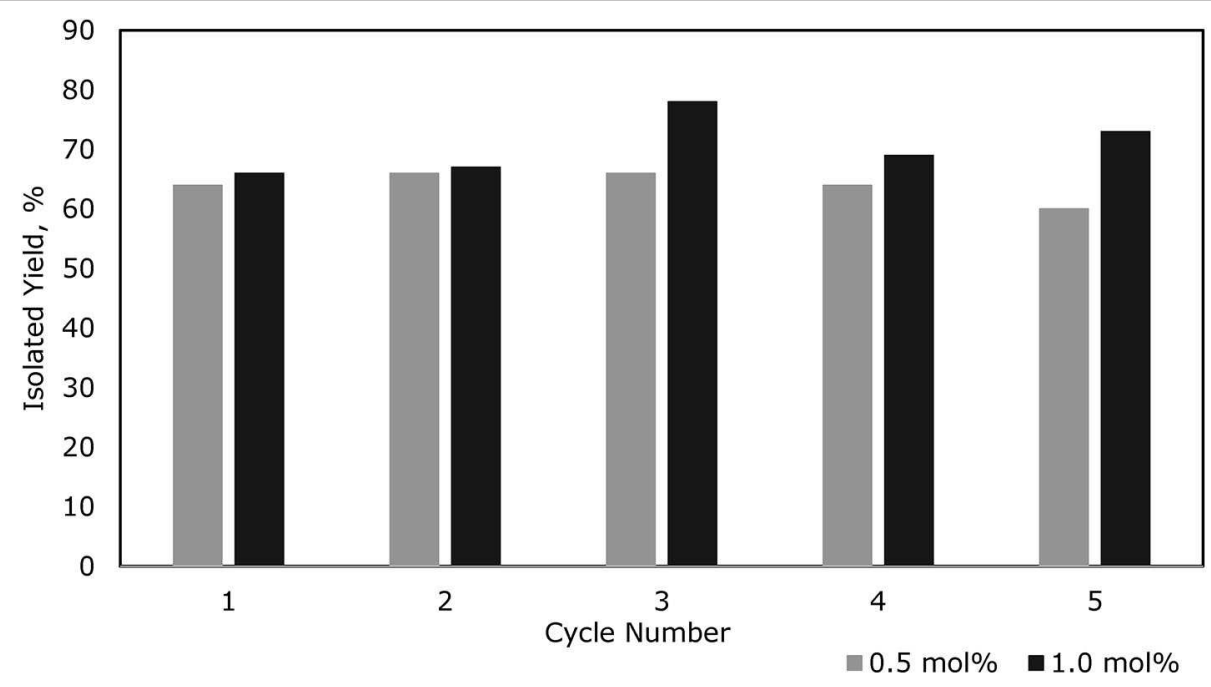

FIGURE 3 | Yields for 3 a over 5 cycles of recycling using 0.5 and 1.0 mol\% catalyst loading.

enhanced in the presence of a solvent as compared to a neat reaction. Overall, these experiments successfully demonstrated the longevity of the $\left(\mathrm{C}_{6} \mathrm{~F}_{5}\right)_{3} \mathrm{~B}\left(\mathrm{OH}_{2}\right)$ catalyst and that it is possible to recycle it at least five times in reactions with the given substrates.

\section{CONCLUSIONS}

The study presented in this article has demonstrated an efficient route from secondary and tertiary hydrosilanes into the corresponding oligosiloxanes using a moisture-stable and recyclable $\left(\mathrm{C}_{6} \mathrm{~F}_{5}\right)_{3} \mathrm{~B}\left(\mathrm{OH}_{2}\right)$ catalyst through either an intermolecular or intramolecular reaction depending on the substrate. Multiple catalytically relevant species and a series of competitive reactions are probable when considering the mechanism involved for the direct synthesis of siloxanes from only hydrosilanes and water. A single catalytic pathway is simply not enough to describe the formation of the disiloxane. The experimental results gathered from control studies suggest that the most feasible route to disiloxanes is where the $\mathrm{Si}-\mathrm{H}$ is partially converted to $\mathrm{Si}-\mathrm{OH}$ followed by a heterodehydrocoupling reaction of $\mathrm{Si}-\mathrm{H} / \mathrm{Si}-\mathrm{OH}$. Moreover, the cross-coupling results show promise for the selective synthesis of unsymmetrical siloxanes under controlled conditions directly from silanes or using a mixture of silanes and silanols or alcohols and this will be the subject of future studies in our group. Nonetheless, given the wide range of hydrosilanes that are commercially available, this protocol should provide an easy route to a large variety of oligosiloxanes. 


\section{DATA AVAILABILITY STATEMENT}

The datasets generated for this study can be found in the CCDC repository $(1987430,1987431)$ or are included in article/Supplementary Material.

\section{AUTHOR CONTRIBUTIONS}

KR-C and VK designed and performed the experiments under the supervision of EL. TS refined the crystal structures. KR-C and VK wrote the paper with editorial support from EL.

\section{FUNDING}

This work was supported by Royal Society of New Zealand, Marsden Fast Start Fund (16-UOA-042).

\section{REFERENCES}

Abele, R., Abele, E., Fleisher, M., Geinberga, S., and Lukevics, E. (2003). Novel fluoride ion mediated synthesis of unsymmetrical siloxanes under phase transfer catalysis conditions. J. Organometal. Chem. 686, 52-57. doi: 10.1016/S0022-328X(03)00286-9

Ai, L., Chen, Y., He, L., Luo, Y., Li S., and Xu, C. (2019). Synthesis of structured polysiloxazanes via a Piers-Rubinsztajn reaction. Chem. Comm. 55, 14019-14022. doi: 10.1039/C9CC07312D

Asao, N., Ishikawa, Y., Hatakeyama, N., Menggenbateer, Yamamoto, Y., Chen, M., et al. (2010). Nanostructured materials as catalysts: nanoporous-gold-catalyzed oxidation of organosilanes with water. Angew. Chem. Int. Ed. 49, 10093-10095. doi: 10.1002/anie.201005138

Ashley, A. E., Thompson, A. L., and O'Hare, D. (2009). Non-metal-mediated homogeneous hydrogenation of $\mathrm{CO}_{2}$ to $\mathrm{CH}_{3} \mathrm{OH}$. Angew. Chem. Int. Ed. 48, 9839-9843. doi: 10.1002/anie.200905466

Bergquist, C., Bridgewater, B. M., Harlan, C. J., Norton, J. R., Friesner R. A., and Parkin, G. (2000). Aqua, alcohol, and acetonitrile adducts of Tris(perfluorophenyl)borane: evaluation of brønsted acidity and ligand lability with experimental and computational methods. J. Am. Chem. Soc. 122, 10581-10590. doi: 10.1021/ja001915g

Beringhelli, T., Maggioni, D., and D'alfonso, G. (2001). 1H and 19F NMR investigation of the reaction of $\mathrm{B}\left(\mathrm{C}_{6} \mathrm{~F}_{5}\right)_{3}$ with water in toluene solution. Organometallics 20, 4927-4938. doi: 10.1021/om010610n

Blackwell, J. M., Foster, K. L., Beck, V. H., and Piers, W. E. (1999). B(C $\left.\mathrm{C}_{6} \mathrm{~F}_{5}\right)_{3}-$ catalyzed silation of alcohols: a mild, general method for synthesis of silyl ethers. J. Org. Chem. 64, 4887-4892. doi: 10.1021/jo9903003

Bradley, D. C., Harding, I. S., Keefe, A. D., Motevalli, M., and Zheng, D. H. (1996). Reversible adduct formation between phosphines and triarylboron compounds. J. Chem. Soc. Dalton Trans. 3931-3936. doi: 10.1039/dt9960003931

Brinker, C. J., and Scherer, G. W. (1990). Sol-Gel Science: The Physics and Chemistry of Sol-Gel Processing. New York, NY: Academic Press.

Brook, M. A. (2018). New control over silicone synthesis using sih chemistry: the piers-rubinsztajn reaction. Chem. Eur. J. 24, 8458-8469. doi: 10.1002/chem.201800123

Cella, J., and Rubinsztajn, S. (2008). Preparation of polyaryloxysilanes and polyaryloxysiloxanes by $\mathrm{B}\left(\mathrm{C}_{6} \mathrm{~F}_{5}\right)_{3}$ catalyzed polyetherification of dihydrosilanes and bis-phenols. Macromolecules 41, 6965-6971. doi: $10.1021 / \mathrm{ma} 800833 \mathrm{c}$

Chauhan, B. P. S., Sarkar, A., Chauhan, M., and Roka, A. (2009). Water as green oxidant: a highly selective conversion of organosilanes to silanols with water. Appl. Organomet. Chem. 23, 385-390. doi: 10.1002/aoc.1528

Cheng, G. J., Drosos, N., Morandi, B., and Thiel, W. (2018). Computational study of $\mathrm{B}\left(\mathrm{C}_{6} \mathrm{~F}_{5}\right)_{3}$-catalyzed selective deoxygenation of 1,2-diols: cyclic and noncyclic pathways. ACS Catal. 8, 1697-1702. doi: 10.1021/acscatal.7b04209

\section{ACKNOWLEDGMENTS}

The authors would like to acknowledge the School of Chemical Sciences at the University of Auckland for a doctoral scholarship (KR-C) as well as the Royal Society of New Zealand Marsden Fast-Start grant for providing financial support as well as a doctoral scholarship (VK). We thank Tatiana Groutso for collecting the single crystal X-ray diffraction data. We would also like to acknowledge the MacDiarmid Institute for financial support.

\section{SUPPLEMENTARY MATERIAL}

The Supplementary Material for this article can be found online at: https://www.frontiersin.org/articles/10.3389/fchem. 2020.00477/full\#supplementary-material

Chojnowski, J., Fortuniak, W., Kurjata, J., Rubinsztajn, S., and Cella, J. A. (2006). Oligomerization of hydrosiloxanes in the presence of tris(pentafluorophenyl)borane. Macromolecules, 39, 3802-3807. doi: $10.1021 / \mathrm{ma} 060080 \mathrm{c}$

Chojnowski, J., Rubinsztajn, S., Cella, J. A., Fortuniak, W., Cypryk, M., Kurjata, J., et al. (2005). Mechanism of the $\mathrm{B}\left(\mathrm{C}_{6} \mathrm{~F}_{5}\right)_{3}$-catalyzed reaction of silyl hydrides with alkoxysilanes. Kinetic and spectroscopic studies. Organometallics, 24, 6077-6084. doi: 10.1021/om050563p

Chojnowski, J., Rubinsztajn, S., Fortuniak, W., and Kurjata, J. (2008). Synthesis of highly branched alkoxysiloxane-dimethylsiloxane copolymers by nonhydrolytic dehydrocarbon polycondensation catalyzed by tris(pentafluorophenyl)borane. Macromolecules, 41, 7352-7358. doi: $10.1021 / \mathrm{ma} 801130 \mathrm{y}$

Diemoz, K. M., Wilson, S. O., and Franz, A. K. (2016). Synthesis of structurally varied 1,3-disiloxanediols and their activity as anion-binding catalysts. Chem Eur. J. 22, 18349-18353. doi: 10.1002/chem.201604103

Dolomanov, O. V., Bourhis, L. J., Gildea, R. J., Howard, J. A. K., and Puschmann, H. (2009). OLEX2: a complete structure solution, refinement and analysis program. J. Appl. Crystallogr. 42, 339-341. doi: 10.1107/S0021889808 042726

Feghali, E., and Cantat, T. (2014). Unprecedented organocatalytic reduction of lignin model compounds to phenols and primary alcohols using hydrosilanes. Chem. Commun. 50, 862-865. doi: 10.1039/C3CC $47655 \mathrm{C}$

Feghali, E., Carrot, G., Thuéry, P., Genre, C., and Cantat, T. (2015). Convergent reductive depolymerization of wood lignin to isolated phenol derivatives by metal-free catalytic hydrosilylation. Energy Environ. Sci. 8, 2734-2743. doi: 10.1039/C5EE01304F

Grubb, W. T. (1954). A rate study of the silanol condensation reaction at $25^{\circ}$ in alcoholic solvents1. J. Am. Chem. Soc. 76, 3408-3414. doi: 10.1021/ja01642a014

Hog, D. T., and Oestreich, M. (2009). B( $\left.\mathrm{C}_{6} \mathrm{~F}_{5}\right)_{3}$-catalyzed reduction of ketones and imines using silicon-stereogenic silanes: stereoinduction by singlepoint binding. Eur. J. Org. Chem. 2009, 5047-5056. doi: 10.1002/ejoc.2009 00796

Hreczycho, G. (2015). An efficient catalytic approach for the synthesis of unsymmetrical siloxanes. Eur. J. Inorg. Chem. 2015, 67-72. doi: 10.1002/ejic.201402904

Hreczycho, G., Kucinski, K., Pawluć, P., and Marciniec, B. (2013). Catalytic synthesis of linear oligosiloxanes and germasiloxanes mediated by scandium trifluoromethanesulfonate. Organometallics 32, 5001-5004. doi: 10.1021/om400581g

Igarashi, M., Kubo, K., Matsumoto, T., Sato, K., Ando,W., and Shimada, S. (2014). $\mathrm{Pd} / \mathrm{C}$-catalyzed cross-coupling reaction of benzyloxysilanes with halosilanes for selective synthesis of unsymmetrical siloxanes. RSC Adv. 4, 19099-19102. doi: $10.1039 / \mathrm{c} 4 \mathrm{ra} 02126 \mathrm{f}$ 
Ison, E. A., Corbin, R. A., and Abu-Omar, M. M. (2005). Hydrogen production from hydrolytic oxidation of organosilanes using a cationic oxorhenium catalyst. J. Am. Chem. Soc. 127, 11938-11939. doi: 10.1021/ja053860u

Jeon, M., Han, J., and Park, J. (2012). Transformation of silanes into silanols using water and recyclable metal nanoparticle catalysts. ChemCatChem 4, 521-524. doi: $10.1002 /$ cctc. 201100456

John, J., Gravel, E., Hagège, A., Li, H., Gacoin, T., and Doris, E. (2011). Catalytic oxidation of silanes by carbon nanotube-gold nanohybrids. Angew. Chem. Int. Ed. 50, 7533-7536. doi: 10.1002/anie.201101993

Jorapur, Y. R., and Shimada, T. (2012). An efficient method for the synthesis of symmetrical disiloxanes from alkoxysilanes using meerwein's reagent. Synlett 23, 1633-1638. doi: 10.1055/s-0031-1290668

Kawakami, Y., Li, Y., Liu, Y., Seino, M., Pakjamsai, C., Oishi, M., et al. (2004). Control of molecular weight, stereochemistry and higher order structure of siloxane-containing polymers and their functional design. Macromol. Res. 12, 156-171. doi: 10.1007/BF03218384

Kaźmierczak, J., and Hreczycho, G. (2018). Nafion as effective and selective heterogeneous catalytic system in O-metalation of silanols and POSS silanols. J. Cat. 367, 95-103. doi: 10.1016/j.jcat.2018.08.024

Kuciński, K., and Hreczycho, G. (2019a). A highly effective route to si$\mathrm{o}$-si moieties through $o$-silylation of silanols and polyhedral oligomeric silsesquioxane silanols with disilazanes. ChemSusChem 12, 1043-1048. doi: $10.1002 /$ cssc. 201802757

Kuciński, K., and Hreczycho, G. (2019b). O-metalation of silanols and POSS silanols over amberlyst-15 catalyst: a facile route to unsymmetrical siloxanes, borasiloxanes and germasiloxanes. Inorg. Chim. Acta 490, 261-266. doi: 10.1016/j.ica.2019.03.025

Kurihara, Y., Yamanoi, Y., and Nishihara, H. (2013). Pd-catalyzed synthesis of symmetrical and unsymmetrical siloxanes. Chem. Comm., 49, 11275-11277. doi: $10.1039 / \mathrm{c} 3 \mathrm{cc} 46294 \mathrm{c}$

Kurjata, J., Fortuniak, W., Rubinsztajn, S., and Chojnowski, J. (2009). B $\left(\mathrm{C}_{6} \mathrm{~F}_{5}\right)_{3}$ catalyzed dehydrocarbon polycondensation of $\mathrm{PhSiH}_{3}$ with $(\mathrm{MeO}) 4 \mathrm{Si}$ as model polyfunctional comonomers in new route to hydrophobic silicone TQ resins. Eur. Polym. J. 45, 3372-3379. doi: 10.1016/j.eurpolymj.2009.10.004

Laengert, S. E., Schneider, A. F., Lovinger, E., Chen, Y., and Brook, M. A. (2017). Sequential functionalization of a natural crosslinker leads to designer silicone networks. Chem. Asian J. 12, 1208-1212. doi: 10.1002/asia.201700160

Lawson, J. R., and Melen, R. L. (2017). Tris(pentafluorophenyl)borane and beyond: modern advances in borylation chemistry. Inorg. Chem. 56, 8627-8643. doi: 10.1021/acs.inorgchem.6b02911

Le Coz, E., Kahlal, S., Saillard, J. Y., Roisnel, T., Dorcet, V., Carpentier J. F. et al. (2019). Barium siloxides and catalysed formation of Si-O-Si' motifs. Chem. Eur. J. 25, 13509-13513. doi: 10.1002/chem.201903676

Lee, M., Ko, S., and Chang, S. (2000). Highly selective and practical hydrolytic oxidation of organosilanes to silanols catalyzed by a ruthenium complex. J. Am. Chem. Soc. 122, 12011-12012. doi: 10.1021/ja003079g

Lee, Y., Seomoon, D., Kim, S., Han, H., Chang, S., and Lee, P. H. (2004). Highly efficient iridium-catalyzed oxidation of organosilanes to silanols. J. Org. Chem. 69, 1741-1743. doi: 10.1021/jo035647r

Liu, T., Yang, F., Li, Y., Ren, L., Zhang, L., Xu, K., et al. (2014). Plasma synthesis of carbon nanotube-gold nanohybrids: efficient catalysts for green oxidation of silanes in water. J. Mater. Chem. A 2, 245-250. doi: 10.1039/C3TA13693K

Longuet, C., Joly-Duhamel, C., and Ganachaud, F. (2007). Copolycondensation of regular functional silane and siloxane in aqueous emulsion using $\mathrm{B}\left(\mathrm{C}_{6} \mathrm{~F}_{5}\right)_{3}$ as a catalyst. Macromol. Chem. Phys. 208, 1883-1892. doi: 10.1002/macp.200700202

Macrae, C. F., Edgington, P. R., Mccabe, P., Pidcock, E., Shields, G. P., Taylor, R., et al. (2006). Mercury: visualization and analysis of crystal structures. J. Appl. Crystallogr. 39, 453-457. doi: 10.1107/S002188980600731X

Madsen, F. B., Javakhishvili, I., Jensen, R. E., Daugaard, A. E., Hvilsted, S., and Skov, A. L. (2014). Synthesis of telechelic vinyl/allyl functional siloxane copolymers with structural control. Polym. Chem. 5, 7054-7061. doi: 10.1039/C4PY00919C

Marciniec, B., Pawluć, P., Hreczycho, G., Macina, A., and Adalska, M. (2008). Silylation of silanols with vinylsilanes catalyzed by a ruthenium complex. Tetrahedron Lett. 49, 1310-1313. doi: 10.1016/j.tetlet.2007.12.091

Mathew, J., Eguchi, K., Nakajima, Y., Sato, K., Shimada, S., and Choe, Y.-K. (2017). Tris(pentafluorophenyl)borane-catalyzed reactions of siloxanes: a combined experimental and computational study. Eur. J. Org. Chem. 2017, 4922-4927. doi: $10.1002 /$ ejoc. 201700760
Matsumoto, K., Oba, Y., Nakajima, Y., Shimada, S., and Sato, K. (2018). Onepot sequence-controlled synthesis of oligosiloxanes. Angew. Chem. Int. Ed. 57, 4637-4641. doi: 10.1002/anie.201801031

Matsumoto, K., Shimada, S., and Sato, K. (2019). Sequence-controlled catalytic one-pot synthesis of siloxane oligomers. Chem. Eur. J. 25, 920-928. doi: $10.1002 /$ chem. 201803565

Matsuo, T., and Kawaguchi, H. (2006). From carbon dioxide to methane: homogeneous reduction of carbon dioxide with hydrosilanes catalyzed by zirconium-borane complexes. J. Am. Chem. Soc. 128, 12362-12363. doi: $10.1021 /$ ja0647250

Mewald, M., and Oestreich, M. (2012). Illuminating the mechanism of the boranecatalyzed hydrosilylation of imines with both an axially chiral borane and silane. Chem. Eur. J. 18, 14079-14084. doi: 10.1002/chem.201202693

Mitsudome, T., Arita, S., Mori, H., Mizugaki, T., Jitsukawa, K., and Kaneda, K. (2008). Supported silver-nanoparticle-catalyzed highly efficient aqueous oxidation of phenylsilanes to silanols. Angew. Chem. Int. Ed. 47, 7938-7940. doi: 10.1002/anie.200802761

Mitsudome, T., Noujima, A., Mizugaki, T., Jitsukawa, K., and Kaneda, K. (2009). Supported gold nanoparticlecatalyst for the selective oxidation of silanes to silanols in water. Chem. Commun. 5302-5304. doi: 10.1039/b910208f

Muzafarov, A. M. (2011). Advances in Polymer Science, Silicon Polymers. Berlin: Springer-Verlag.

Neumann, B., Vincent, B., Krustev, R., and Müller, H. J. (2004). Stability of various silicone oil/water emulsion films as a function of surfactant and salt concentration. Langmuir 20, 4336-4344. doi: 10.1021/la035517d

Parks, D. J., Blackwell, J. M., and Piers, W. E. (2000). Studies on the mechanism

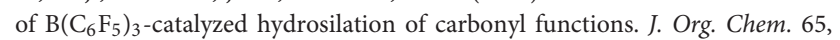
3090-3098. doi: 10.1021/jo991828a

Parks, D. J., and Piers, W. E. (1996). Tris(pentafluorophenyl)boron-catalyzed hydrosilation of aromatic aldehydes, ketones, and esters. J. Am. Chem. Soc. 118, 9440-9441. doi: 10.1021/ja961536g

Pattanaik, S., and Gunanathan, C. (2019). Cobalt-catalyzed selective synthesis of disiloxanes and hydrodisiloxanes. ACS Cataly. 9, 5552-5561. doi: $10.1021 /$ acscatal.9b00305

Piers, W. E. (2004). The chemistry of perfluoroaryl boranes. Adv. Organomet. Chem. 52, 1-76. doi: 10.1016/s0065-3055(04)52001-4

Rabanzo-Castillo, K. M., Hanif, M., Söhnel, T., and Leitao, E. M. (2019). Synthesis, characterisation and electronic properties of naphthalene bridged disilanes. Dalton Trans. 48, 13971-13980. doi: 10.1039/C9DT 03058A

Rendler, S., and Oestreich, M. (2008). Conclusive evidence for an $\mathrm{SN}_{2}-\mathrm{Si}$ mechanism in the $\mathrm{B}\left(\mathrm{C}_{6} \mathrm{~F}_{5}\right)_{3}$-catalyzed hydrosilylation of carbonyl compounds: implications for the related hydrogenation. Angew. Chem. Int. Ed. 47, 5997-6000. doi: 10.1002/anie.200801675

Rubinsztajn, S., and Cella, J. A. (2005). A new polycondensation process for the preparation of polysiloxane copolymers. Macromolecules 38, 1061-1063. doi: $10.1021 / \mathrm{ma} 047984 \mathrm{n}$

Sakata, K., and Fujimoto, H. (2013). Quantum chemical study of $B\left(\mathrm{C}_{6} \mathrm{~F}_{5}\right)_{3}$ catalyzed hydrosilylation of carbonyl group. J. Org. Chem. 78, 12505-12512. doi: $10.1021 /$ jo $402195 \mathrm{x}$

Sawama, Y., Masuda, M., Yasukawa, N., Nakatani, R., Nishimura, S., Shibata, K., et al. (2016). Disiloxane synthesis based on silicon-hydrogen bond activation using gold and platinum on carbon in water or heavy water. J. Org. Chem. 81, 4190-4195. doi: 10.1021/acs.joc.6b00556

Schneider, A. F., Laidley, E., and Brook, M. A. (2019). Facile synthesis of $\mathrm{Cx}(\mathrm{AB}) \mathrm{yCx}$ triblock silicone copolymers utilizing moisture mediated living-end chain extension. Macromol. Chem. Phys. 220:1800575. doi: 10.1002/macp.201800575

Scott, D. J., Simmons, T. R., Lawrence, E. J., Wildgoose, G. G., Fuchter, M. J., and Ashley, A. E. (2015). Facile protocol for water-tolerant "frustrated lewis pair"-catalyzed hydrogenation. ACS Catal. 5, 5540-5544. doi: 10.1021/acscatal.5b01417

Sheldrick, G. (2015). SHELXT - integrated space-group and crystalstructure determination. Acta Crystallogr. Sect. A 71, 3-8. doi: $10.1107 /$ S2053273314026370

Shimizu, K., Kubo, T., and Satsuma, A. (2012a). Surface oxygen-assisted pd nanoparticle catalysis for selective oxidation of silanes to silanols. Chem. Eur. J. 18, 2226-2229. doi: 10.1002/chem.201103088 
Shimizu, K.-I., Shimura, K., Imaiida, N., and Satsuma, A. (2012b). Heterogeneous nickel catalyst for selective hydration of silanes to silanols. J. Mol. Catal. A Chem. 365, 50-54. doi: 10.1016/j.molcata.2012.08.007

Shinke, S., Tsuchimoto, T., and Kawakami, Y. (2007). Stereochemistry in Lewis acid-catalyzed silylation of alcohols, silanols, and methoxysilanes with optically active methyl(1-naphthyl)phenylsilane. Silicon Chem. 3, 243-249. doi: 10.1007/s11201-007-9026-y

Spek, A. (2003). Single-crystal structure validation with the program PLATON. J. App. Cryst. 36, 7-13. doi: 10.1107/S00218898020 22112

Sridhar, M., Ramanaiah, B. C., Narsaiah, C., Kumara Swamy, M., Mahesh, B., and Kumar Reddy, M. K. (2009). An efficient and simple method for the preparation of symmetrical disiloxanes from hydrosilanes by Lewis acid-catalyzed air oxidation. Tetrahedron Lett., 50, 7166-7168. doi: 10.1016/j.tetlet.2009. 10.020

Szawiola, A. M., De Melo Souza, N., Lessard, B. H., and Bender, T. P. (2017). Phenoxylated siloxane-based polymers via the Piers-Rubinsztajn process. Polym. Int. 66, 1324-1328. doi: 10.1002/pi.5396

Tan, S. T., Kee, J. W., and Fan, W. Y. (2011). Catalytic hydrogen generation from the hydrolysis of silanes by ruthenium complexes. Organometallics, 30, 4008-4013. doi: 10.1021/om200256h

Thompson, J. L., and Davies, H. M. (2007). Enhancement of cyclopropanation chemistry in the silver-catalyzed reactions of aryldiazoacetates. J. Am. Chem. Soc. 129, 6090-6091. doi: 10.1021/ja0 $69314 y$

Tsuchido, Y., Kanda, A., and Osakada, K. (2020). Gold (I) complexes with chloro(diaryl)silyl ligand. Stoichiometric reactions and catalysis for O-functionalization of organosilane. Tetrahedron 76:131076. doi: 10.1016/j.tet.2020.131076

Uchida, H., Kabe, Y., Yoshino, K., Kawamata, A., Tsumuraya, T., and Masamune, S. (1990). General strategy for the systematic synthesis of oligosiloxanes. Silicone dendrimers. J. Am. Chem. Soc. 112, 7077-7079. doi: 10.1021/ja001 $75 \mathrm{a} 062$

Wang, D., Klein, J., and Mejía, E. (2017). Catalytic systems for the crosslinking of organosilicon polymers. Chem. Asian J. 12, 1180-1197. doi: 10.1002/asia.201700304
Wu, C., Yu, J., Li, Q., and Liu, Y. (2017). High molecular weight cyclic polysiloxanes from organocatalytic zwitterionic polymerization of constrained spirocyclosiloxanes. Polym. Chem. 8, 7301-7306. doi: 10.1039/C7PY01499F

Yi, M., Chen, X., Wu, S., Ge, J., Zhou, X., and Yin, G. (2018). Fabrication of reactive poly(Phenyl-Substituted Siloxanes/Silsesquioxanes) with $\mathrm{Si}-\mathrm{H}$ and alkoxy functional groups via the piers-rubinsztajn reaction. Polymers 10:1006. doi: $10.3390 /$ polym 10091006

Yu, Y., Zhu, Y., Bhagat, M. N., Raghuraman, A., Hirsekorn, K. F., Notestein, J. M., et al. (2018). Mechanism of regioselective ring-opening reactions of 1,2-epoxyoctane catalyzed by tris(pentafluorophenyl)borane: a combined experimental, density functional theory, and microkinetic study. ACS Catal. 8, 11119-11133. doi: 10.1021/acscatal.8b02632

Zhang, H., Xue, L., Li, J., and Ma, Q. (2020). Hyperbranched polycarbosiloxanes: synthesis by piers-rubinsztajn reaction and application as precursors to magnetoceramics. Polymers 12:672. doi: 10.3390/polym12030672

Zhang, J., Chen, Y., and Brook, M. A. (2014). Reductive degradation of lignin and model compounds by hydrosilanes. ACS Sust. Chem. Eng. 2, 1983-1991. doi: $10.1021 /$ sc500302j

Zhang, Q., Fu, M. C., Yu, H. Z., and Fu, Y. (2016). Mechanism of boron-catalyzed $\mathrm{N}$-alkylation of amines with carboxylic acids. J. Org. Chem. 81, 6235-6243. doi: 10.1021/acs.joc.6b00778

Zhou, D., and Kawakami, Y. (2005). Tris(pentafluorophenyl)borane as a superior catalyst in the synthesis of optically active Sio-containing polymers. Macromolecules 38, 6902-6908. doi: 10.1021/ma050329a

Conflict of Interest: The authors declare that the research was conducted in the absence of any commercial or financial relationships that could be construed as a potential conflict of interest.

Copyright (C) 2020 Rabanzo-Castillo, Kumar, Söhnel and Leitao. This is an openaccess article distributed under the terms of the Creative Commons Attribution License (CC BY). The use, distribution or reproduction in other forums is permitted, provided the original author(s) and the copyright owner(s) are credited and that the original publication in this journal is cited, in accordance with accepted academic practice. No use, distribution or reproduction is permitted which does not comply with these terms. 